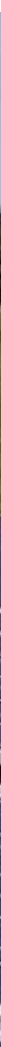

Task 12 PV Sustainability

\title{
Preliminary Environmental and Financial Viability Analysis of Circular Economy Scenarios for Satisfying PV System Service Lifetime 2021
}




\section{What is IEA PVPS TCP?}

The International Energy Agency (IEA), founded in 1974, is an autonomous body within the framework of the Organization for Economic Cooperation and Development (OECD). The Technology Collaboration Programme (TCP) was created with a belief that the future of energy security and sustainability starts with global collaboration. The programme is made up of 6.000 experts across government, academia, and industry dedicated to advancing common research and the application of specific energy technologies.

The IEA Photovoltaic Power Systems Programme (IEA PVPS) is one of the TCP's within the IEA and was established in 1993. The mission of the programme is to "enhance the international collaborative efforts which facilitate the role of photovoltaic solar energy as a cornerstone in the transition to sustainable energy systems." In order to achieve this, the Programme's participants have undertaken a variety of joint research projects in PV power systems applications. The overall programme is headed by an Executive Committee, comprised of one delegate from each country or organisation member, which designates distinct 'Tasks,' that may be research projects or activity areas.

The IEA PVPS participating countries are Australia, Austria, Belgium, Canada, Chile, China, Denmark, Finland, France, Germany, Israel, Italy, Japan, Korea, Malaysia, Mexico, Morocco, the Netherlands, Norway, Portugal, South Africa, Spain, Sweden, Switzerland, Thailand, Turkey, and the United States of America. The European Commission, Solar Power Europe, the Smart Electric Power Alliance (SEPA), the Solar Energy Industries Association and the Cop- per Alliance are also members.

Visit us at: www.iea-pvps.org

\section{What is IEA PVPS Task 12?}

Task 12 aims at fostering international collaboration in safety and sustainability that is crucial for assuring PV grows to levels making it a major contribution to the needs of the member countries and the world. The overall objectives of Task 12 are to 1. quantify the environmental profile of PV in comparison to other energy technologies, 2 . investigate end-of-life management options for PV systems as deployment increases and older systems are decommissioned, and 3. define and address environmental health and safety and other sustainability issues that are important for market growth. The first objective of this task is well served by life cycle assessments (LCAs) that describe the energy, material, and emission flows in all the stages of the PV life cycle. The second objective is addressed through analysis of strategies including recycling and other circular economy pathways. For the third objective, Task 12 develops methods to quantify risks and opportunities on topics of stakeholder interest. Task 12 is operated jointly by the National Renewable Energy Laboratory (NREL) and the University of New South Wales (UNSW Sydney). Support from the U.S. Department of Energy and UNSW are gratefully acknowledged.

Further information on the activities and results of the task can be found at: https://iea-pvps.org/research-tasks/pvsustainability/.

\section{Authors}

> Main Content: N. Rajagopalan, A. Smeets, K. Peeters, S. De Regel, T. Rommens, K. Wang, P. Stolz, R. Frischknecht, G. Heath, and D. Ravikumar

Editor: G. Heath, J Zuboy

\section{DISCLAIMER}

The IEA PVPS TCP is organised under the auspices of the International Energy Agency (IEA) but is functionally and legally autonomous. Views, findings and publications of the IEA PVPS TCP do not necessarily represent the views or policies of the IEA Secretariat or its individual member countries

\section{COVER PICTURE}

Waasland Cohousing Community (Sint-Niklaas, Belgium). For this PV installation, 226 second-life PV modules were combined with 5 new PV modules. (Photo credit: CIRCUSOL) 


\title{
Preliminary Environmental and Financial Viability Analysis of Circular Economy Scenarios for Satisfying PV System Service Lifetime
}

\author{
IEA PVPS \\ Task 12: PV Sustainability
}

\section{Report IEA-PVPS T12-21:2021 \\ November 2021}

\section{ISBN 978-3-907281-23-9}

\section{Operating Agents:}

Garvin Heath, National Renewable Energy Laboratory, Golden, CO, USA José Bilbao, University of New South Wales, Sydney, Australia

\section{Authors:}

PART A: Neethi Rajagopalan, Karolien Peeters, Tom Rommens, Ke Wang, Philippe Stolz, Rolf Frischknecht, Garvin Heath, Dwarakanath Ravikumar

PART B: Anse Smeets, Sofie De Regel, Tom Rommens, Ke Wang, Garvin Heath, Dwarakanath Ravikumar

Citation: N. Rajagopalan, A. Smeets, K. Peeters, S. De Regel, T. Rommens, K. Wang, P. Stolz, R. Frischknecht, G. Heath, D. Ravikumar. 2021. Preliminary Environmental and Financial Viability Analysis of Circular Economy Scenarios for Satisfying PV System Service Lifetime. International Energy Agency (IEA) PVPS Task 12, Report T12-21:2021. ISBN 978-3-90728123-9. 


\section{TABLE OF CONTENTS}

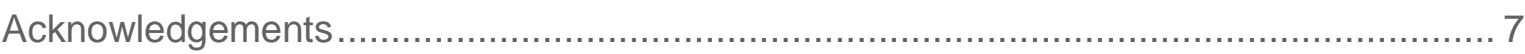

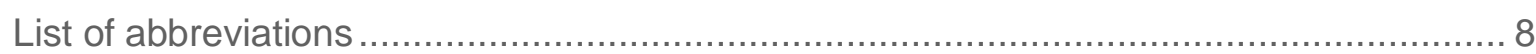

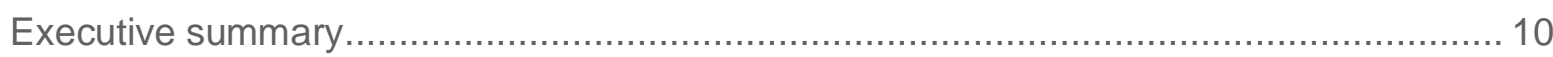

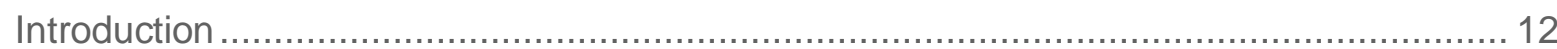

PART A ENVIRONMENTAL LIFE CYCLE ASSESSMENT OF SATISFYING THE LIFETIME OF PREMATURELY DECOMMISSIONED PV PANELS ..................... 13

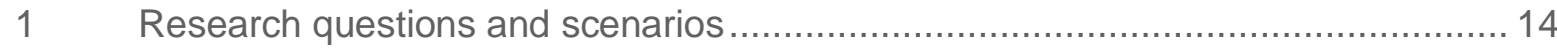

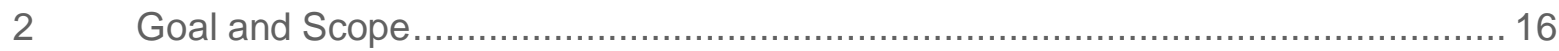

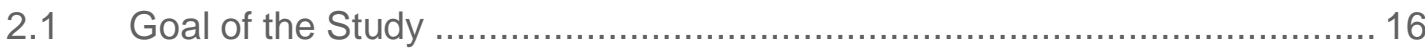

2.2 Scope of the Study and System Boundaries …...................................... 16

2.3 Type of Life Cycle Assessment ..................................................... 16

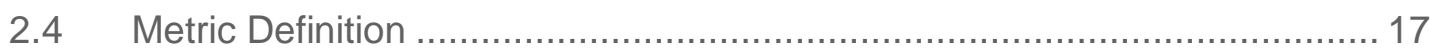

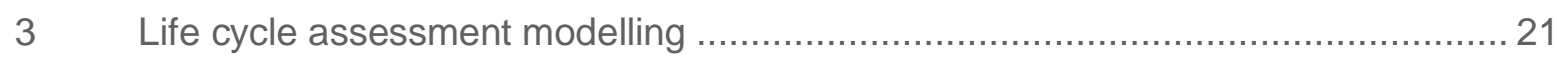

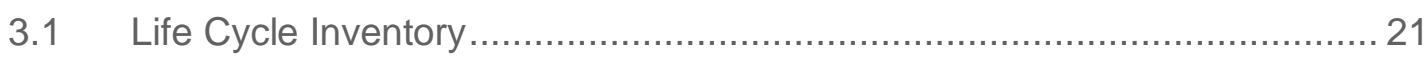

3.2 Life Cycle Impact Assessment ........................................................... 25

3.3 Definition of Study Cases .............................................................. 27

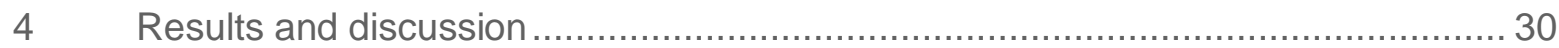

4.1 Base Case: Impact of Service Lifetime .............................................. 30

4.2 Sensitivity Assessment: Impact of Junction Box Repair to Satisfy the

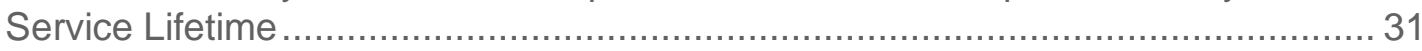

4.3 Sensitivity Assessment: Impact of Transportation Before Reuse to

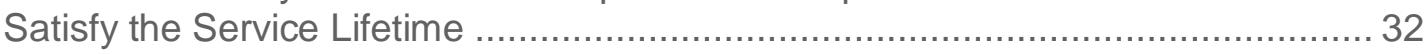

4.4 Sensitivity Assessment: Impact of Technology Evolution/Revolution .......... 33

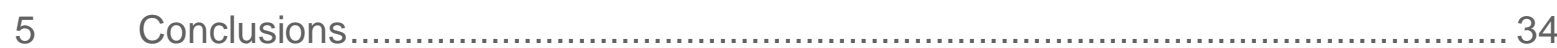

PART B FINANCIAL VIABILITY ANALYSIS OF SATISFYING THE LIFETIME OF PREMATURELY DECOMMISSIONED PV PANELS …...................................... 35

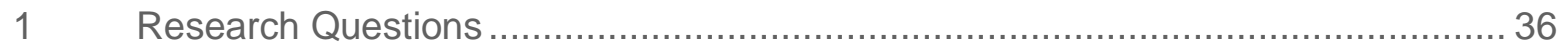

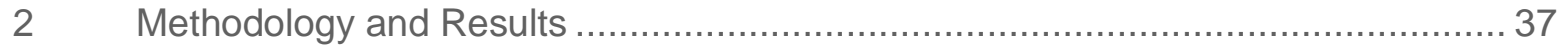

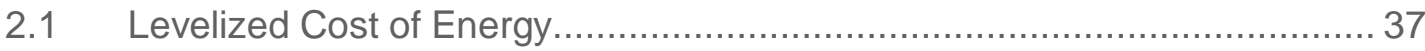

2.2 Demand Side: Willingness to Pay for Prematurely Decommissioned PV 38

2.3 Supply Side: Willingness to Send Prematurely Decommissioned PV to Reuse or Recycle..... 


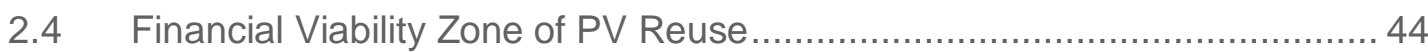

3 Reuse of prematurely decommissioned pv panels in practice .............................. 45

3.1 LCOE for Residential Self-Consumption................................................. 45

3.2 Beyond LCOE for the Utility Market ................................................... 49

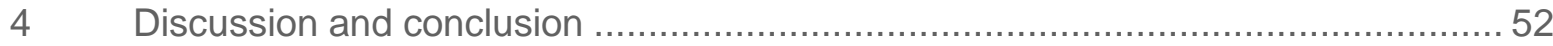

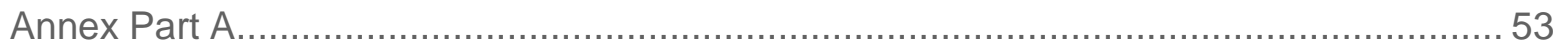

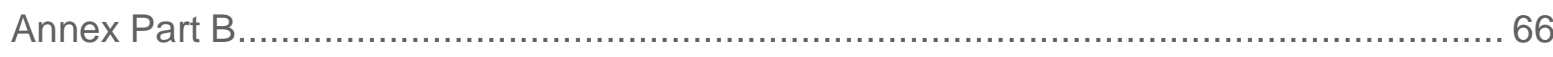

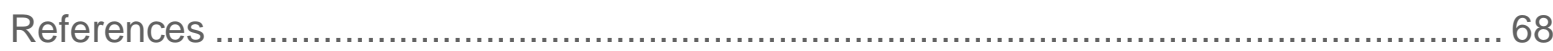




\section{ACKNOWLEDGEMENTS}

This paper received valuable contributions from several IEA-PVPS Task 12 members and other international experts.

The authors acknowledge the valuable contribution of partners and stakeholders of the CIRCUSOL project. This project has received funding from the European Union's Horizon 2020 research and innovation programme under grant agreement 776680 .

Garvin Heath and Dwarakanath Ravikumar are employees of the National Renewable Energy Laboratory (NREL) which is operated by Alliance for Sustainable Energy, LLC for the U.S. Department of Energy (DOE) under Contract No. DE-AC36-08GO28308. Funding for NREL was provided by U.S. Department of Energy Office of Energy Efficiency and Renewable Energy's Solar Energy Technologies Office. The views expressed in the article do not necessarily represent the views of the DOE or the U.S. Government. 


\section{LIST OF ABBREVIATIONS}

\begin{tabular}{|c|c|}
\hline APAC & Asia \& Pacific \\
\hline BOS & balance of systems \\
\hline CAPEX & capital expenses \\
\hline $\mathrm{CH}$ & Switzerland \\
\hline CTUe & comparative toxicity unit for ecosystems \\
\hline CTUh & comparative toxicity unit for humans \\
\hline $\begin{array}{l}\text { Disease } \\
\text { inc }\end{array}$ & impact on human health \\
\hline EF & Environmental Footprint \\
\hline El & environmental impact \\
\hline EOL & end of life \\
\hline $\mathrm{Eq}$ & equivalent \\
\hline EU & European Union \\
\hline EURO4 & European emissions standard \\
\hline FU & functional unit \\
\hline GLO & global \\
\hline $\mathrm{HH}$ & Human health \\
\hline IEA & International Energy Agency \\
\hline $\mathrm{KPI}$ & key performance indicator \\
\hline LCA & life cycle assessment \\
\hline $\mathrm{LCl}$ & life cycle inventory \\
\hline LCIA & life cycle impact assessment \\
\hline LCOE & levelized cost of energy \\
\hline $\mathrm{mPts}$ & millipoints \\
\hline multi-Si & multi-crystalline silicon \\
\hline NPV & net present value \\
\hline OPEX & operational expenses \\
\hline PEF & Product Environmental Footprint \\
\hline PEFCR & Product Environmental Footprint Category Rules \\
\hline PV & photovoltaic \\
\hline PVPS & Photovoltaic Power Systems \\
\hline RER & Representative European Region \\
\hline
\end{tabular}


tkm ton-kilometre (unit for transport services)

U unit process

VAT value-added tax

WACC weighted average cost of capital

WEEE Waste Electrical \& Electronic Equipment

WTP willingness to pay 


\section{EXECUTIVE SUMMARY}

PV deployment has grown rapidly in recent decades, and this growth is expected to continue. At the same time, the rapid increase in PV panel efficiencies offers the opportunity to repower/revamp existing installations-replacing operational, lower-efficiency panels before the end of their 30-year service lifetime with newer, higher-efficiency panels. As a result, an increasing volume of PV panels could be decommissioned well before reaching the end of their 30-year service lifetime.

Two broad strategies can be applied to manage the expected increase in decommissioned PV panels: (i) recycle prematurely decommissioned panels, and (ii) prevent recycling of these panels by satisfying the typical service lifetime of 30 years through circular economy strategies such as repair and reuse. Each strategy presents an environmental and economic trade-off. Retaining and satisfying the lifetime of the older, lower-efficiency panels avoids environmental burdens from recycling or landfilling but incurs burdens from additional repair and forgoing the opportunity to install newer panels with greater electricity-generation capabilities.

This study assesses whether satisfying the expected service lifetime of a PV system through circular economy scenarios generates a greater environmental and financial benefit than recycling used panels and installing newer panels with higher efficiencies. The circular economy scenarios include repair and reuse of the PV system. Specifically, the study determines whether it is better for the environment to keep a PV panel in use for its 30-year service life after accounting for potential repair and additional transportation, or to replace older panels with more efficient new ones. In addition, we explore whether satisfying the service lifetime of PV panels proves competitive with the recycling route from a financial perspective.

Part A of this study focuses on the PV system and quantifies the trade-offs between the environmental burdens and benefits of satisfying the lifetime of a prematurely decommissioned PV system through repair or direct reuse. Part B focuses on the market conditions that favour either (i) a change in ownership (i.e., from the owner who supplies the decommissioned PV system to the next owner who demands the system for reuse), or (ii) recycling of the decommissioned PV system.

The environmental analysis consists of modelled scenarios with different lifetimes of the PV panels $(30,15$, and 10 years). The time horizon is 30 years in all scenarios. The maximum service lifetime is 30 years for a panel and 15 years for an inverter. A life cycle assessment approach is used to model the environmental aspects of the PV system. The functional unit is the generation of $1 \mathrm{kWh}$ of electricity. The environmental impact of $\mathrm{PV}$ is dominated by its production phase, followed by the end-of-life stage. The impact of the use phase (mainly water used for cleaning) constitutes less than $0.1 \%$ of the total life cycle impact (1).

Based on Part A of the study, satisfying a 30-year service lifetime of PV panels appears favourable from an environmental perspective, at least for the cases examined. In other words, it is better for the environment to keep a panel in use for its 30 -year lifetime instead of replacing it with new, more efficient panels. Adding repair activities and/or additional transport is unlikely to change this conclusion. Drastic technological revolutions in panel efficiency, production and recycling process efficiency, or both are also unlikely to change this conclusion. This analysis uses a constant system-specific yield. In real life, PV reuse may involve changes in geographical location and thus solar irradiation and performance ratio. In addition, the study analyses multi-crystalline silicon technology, which 
limits the validity of the conclusions to this technology. Multi-crystalline silicon was chosen because it was the technology with the highest market share at the time of the analysis (2).

Based on analysis of a ground-mount, utility-scale PV system in Part B, satisfying the 30-year service lifetime of PV panels proves financially competitive to the "recycle and acquire new" scenario under certain conditions, from a theoretical levelized cost of electricity (LCOE) perspective. This is the case for relatively young panels (up to around 10 years old) with few or no defects. Although we do not account for testing and recertification costs, these costs could be a determining factor for the success of the reuse business case.

Yet, in practice, satisfying the 30-year service lifetime of PV through reuse in the residential market does not appear to be financially desirable owing to surface-area restrictions as well as the lower remaining power density and limited remaining lifetimes of prematurely decommissioned panels. In addition, our analysis of PV as a utility-scale investment-using net present value as the key performance indicator-suggests that new panels are more attractive than prematurely decommissioned panels in this context as well, without and especially with surface-area limits.

In reality, the financial viability of the reuse business case is influenced by additional countryand case-specific parameters, such as the grid tariffs that drive revenue and can fluctuate substantially. These revenues-together with PV efficiency improvements, price changes, and area restrictions-drive investment decisions 


\section{INTRODUCTION}

Deployment of photovoltaics (PV) has been growing rapidly over recent decades, and growth is expected to continue given the urgency and national commitments to climate change mitigation. As the PV power market booms, so will the volume of PV panels reaching end of life (EOL). As projected in the 2016 International Renewable Energy Agency/Photovoltaic Power Systems Programme (PVPS) Task 12 report (3), a significant amount of the PV "waste" stream will be panels with early defects, often within the first few years of their service life. In addition, healthy panels can be decommissioned well before reaching their 30-year service lifetime. This may be due to insurance claims, when it is often more economical to replace the entire string even if only one panel is damaged. It may also be due to repowering (also known as revamping), when existing panels are replaced by higher-efficiency panels. With rapid PV efficiency improvements and an increasing number of installations becoming 10 years old or older, repowering/revamping likely will scale up in the near future. Therefore, an increasing volume of PV panels will be decommissioned well before reaching the end of their service lifetime (as defined by warranty period, which is typically 25-30 years).

There are three basic routes to properly manage prematurely decommissioned PV panels: landfill, recycle, and reuse. Although landfilling PV is common in some nations, often due to lack of policy mandates for other options and lack of economically viable recycling options, it is clearly not a sustainable route because valuable raw materials are lost. Landfilling of PV is being phased out in the European Union (EU), where waste recycling targets are in place (4). Therefore, landfilling is not considered in this report. Recycling refers to turning the PV panels - by physical, thermal, or chemical processes-into secondary raw materials such as glass, metal, and polymers. This route is considered as an EOL option for decommissioned panels in this report. This report also analyses two reuse pathways for satisfying the service lifetimes of prematurely decommissioned panels: with interventions (i.e. ,repair) and without interventions (direct reuse). Because there is no literature or market for prematurely decommissioned PV panels whose lifetime can be satisfied through repair or direct reuse, the results presented in this study should be considered preliminary.

While recycling may be the default route for panels at the end of their technical life, prematurely decommissioned panels can be recycled or repaired and reused. The circular economy prioritizes satisfying the service lifetime over recycling based on the principle of keeping products at their original and highest value in the economy for as long as possible. In practice, the potential to satisfy the lifetime of a prematurely decommissioned PV panel through repair or direct reuse is often considered financially unattractive, and this option exists today only as a niche. Furthermore, rapid technology innovation cycles might lead to environmental tradeoffs between satisfying the service lifetime and recycling.

This report has the following aims:

- Assess whether satisfying the lifetime of a prematurely decommissioned PV panel is environmentally more favourable than recycling (as suggested by circular economy principles) and what the boundary conditions may be. Different scenarios, all with a time horizon of 30 years, are compared using a life cycle assessment (LCA) approach (Part A).

- Preliminarily explore whether satisfying the lifetime of a PV system proves competitive with the "recycle and buy new" route from a financial perspective. This analysis accounts for supply and demand perspectives for prematurely decommissioned PV panels, focusing on two case studies (Part B). 


\section{PART A}

\section{ENVIRONMENTAL LIFE CYCLE ASSESSMENT OF SATISFYING THE LIFETIME OF PREMATURELY DECOMMISSIONED PV PANELS}




\section{RESEARCH QUESTIONS AND SCENARIOS}

This study is guided by the following research questions:

- Is it better for the environment to keep a PV panel in use until the end of its technical life, or to replace older panels with more efficient new ones?

- If satisfying the service lifetime of the PV panel involves repair and/or additional transportation, what impact do these factors have on the conclusion?

In this study, the "PV panel" consists of a PV module and a junction box (Figure 1). The balance of systems (BOS) encompasses all other components of the PV system. The BOS consists of an inverter, lightning protection, cabling in the PV panel area, fuse box, cabling from the PV panels to the inverter, and cabling from the inverter to the electric meter and the mounting system. The most important function of the BOS components is to regulate and monitor the energy produced by the PV panels. The inverter transforms direct current (DC) from the PV array into a form of alternating current $(\mathrm{AC})$ electricity that can be connected to the electric grid (5).

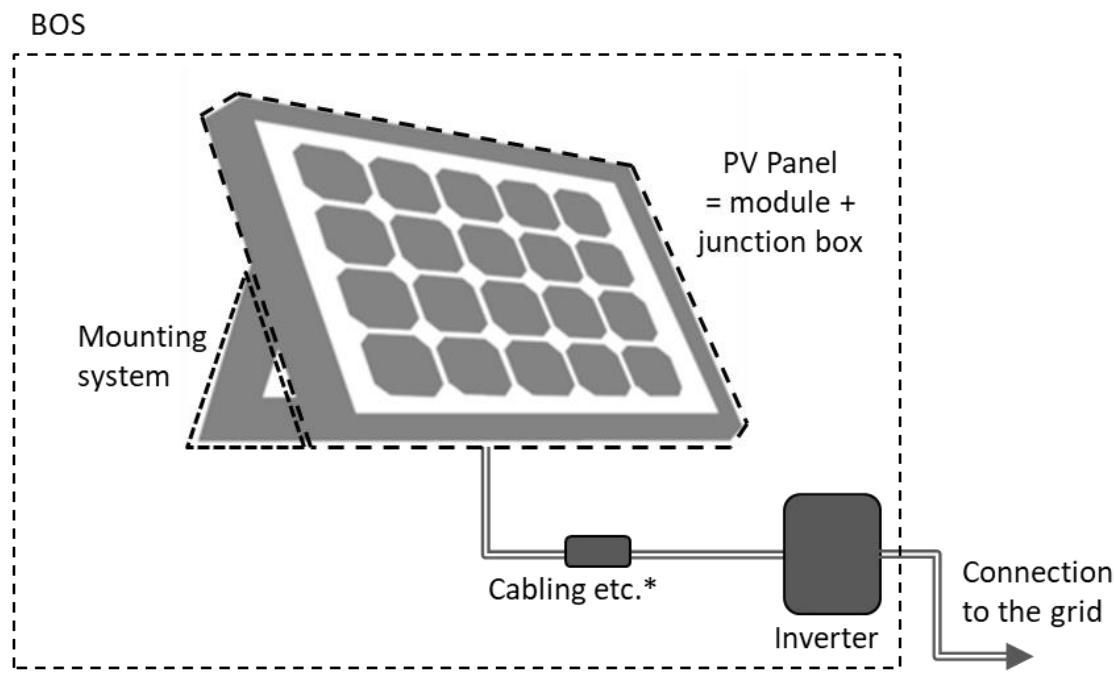

Figure 1: PV system components discussed in this study (simplified presentation)

*The study looks at one PV panel and takes into account the part of the BOS (mounting system, inverter, cabling, etc.) that can be attributed to a single panel.

To answer the research questions, this study uses LCA to model environmental impact over the expected service lifetime of 30 years and in premature-decommissioning scenarios assuming 15- or 10-year lifetimes. The analysis period is 30 years in all scenarios. Replacement of BOS components is also considered.

The technical lifetime of a panel is assumed to be 30 years (6), and this study considers 30 years to be the maximum service life of the installation. The maximum service life of an inverter is assumed to be 15 years. In the scenario where the maximum service life of 30 years is reached, PV panels are kept in use for 30 years and then sent for recycling. First, the simplest situation is considered, with the panels kept in use without need for repair or additional transport throughout the 30 years. We then use sensitivity assessments to consider situations in which repair and/or additional transport are needed to satisfy the service lifetime of the panels (Figure 2). Repair activities include replacement of diodes or junction boxes. These are 
two of the failure modes identified by CIRCUSOL (members of which also serve as International Energy Agency [IEA] PVPS Task 13 experts) as the best candidates for repair (7) and for which data are available to model the environmental impact.

When lifetimes are less than 30 years, decommissioned PV panels are replaced with new, higher-efficiency panels for technical or economic reasons, such as a loss of performance of one panel in a string or the availability of more efficient panels. If the service lifetime is 10 years, then the panels are replaced every 10 years, and three product cycles occur over a 30year time horizon. If the service lifetime is 15 years, then two product cycles occur. In the scenarios with 10- or 15-year panel service lifetimes, the decommissioned panels are recycled after 10 or 15 years of use and replaced with newer, more efficient panels. In the scenario with a 30-year panel lifetime, panels are recycled when they reach their full technical life of 30 years.

For all scenarios and sensitivity assessments, boundary conditions such as location and performance ratio are kept equal, meaning that the system-specific yield is assumed to be the same for all scenarios.

\section{Baseline Scenarios}

a)

Base scenario: panel service lifetime = technical lifetime ( 30 years); no transport or repair activities

b)

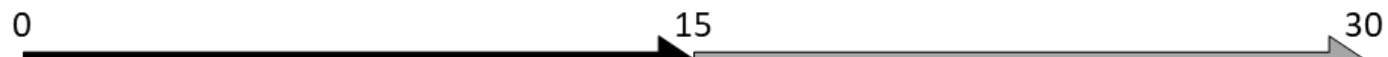

Service lifetime = $\mathbf{1 5}$ years; panels are decommissioned after $\mathbf{1 5}$ years, sent to recycling, and replaced by new, more efficient panels

c)

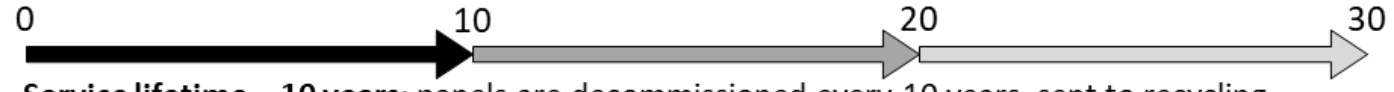

Service lifetime $\mathbf{=} \mathbf{1 0}$ years; panels are decommissioned every 10 years, sent to recycling, and replaced by new, more efficient panels

\section{Sensitivity analyses}

1) 0

Additional environmental impact of repair

2)

Additional environmental impact of transportation to a new location

3)

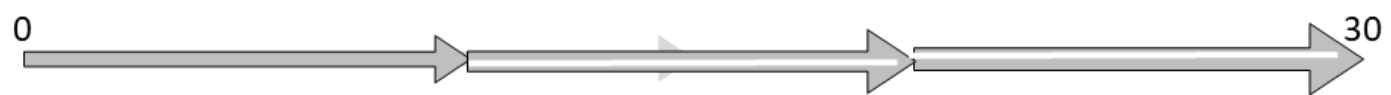

Impact of (hypothetical) projections for advances in peak power and panel efficiency.

Figure 2: General approach towards scenarios studied in this report (see Figure 3 for details) 


\section{GOAL AND SCOPE}

\subsection{Goal of the Study}

The goal of the study is to build up preliminary knowledge about the possibilities and limitations of the circular economy for the PV industry. This part of the study looks at the environmental impact of keeping a panel in use until the end of its service lifetime of 30 years rather than replacing it with a new, more efficient panel before its service lifetime is reached.

This LCA study was carried out within CIRCUSOL, an Innovation Action project funded by the Horizon 2020 program of the European Commission. CIRCUSOL aims to unleash the full potential of circular business models in simultaneously delivering environmental, economic, and user benefits. The LCA results are published for the public by means of this report. The study is in line with the Methodology Guidelines on Life Cycle Assessment of Photovoltaic Electricity put forward by IEA PVPS Task 12 (8).

\subsection{Scope of the Study and System Boundaries}

The product system is a multi-crystalline silicon panel mounted on a flat roof, including BOS as described in Section 1. Multi-crystalline silicon is assumed because it is the technology with the highest market share at the time of the analysis (9). The panel has 60 cells with an area of $1,6 \mathrm{~m}^{2}$, weight of $13,2 \mathrm{~kg}$, and peak power of $235,2 \mathrm{~W} /$ panel in the first year. The peak power is a variable in this study. In some scenarios, panels are replaced with newer, more efficient ones. The peak power of the newer panels is higher (see calculations in Section 2.4). The inverter used in the product system has a capacity of $2,5 \mathrm{~kW}$.

The environmental impact of PV is dominated by its production phase, followed by the EOL phase. The impact in the use phase (mainly water use for cleaning) is negligible: less than $0,1 \%$ of total impacts in most relevant impact categories (1). Life cycle stages included in the analysis are raw material production, production of panel and BOS, transport to installation, and EOL. The use phase is streamlined ${ }^{1}$ because of its low contribution to environmental impact, except in sensitivity assessments where the influence of repair or transportation during the service life is tested. Maintenance activities are streamlined, as is transport to EOL.

\subsection{Type of Life Cycle Assessment}

This study employs an attributional LCA using a process-based approach. It takes into account current performance and the performance of expected future developments in scenarios in which panels are replaced with newer, more efficient ones. The bill of materials for the future developments is unknown, so the study uses the bill of materials for current systems. To address this uncertainty, the influence of future improvements in technology on the results is tested via sensitivity assessment.

\footnotetext{
${ }^{1}$ Streamlining is the process of omitting life cycle stages that are the same for all the considered scenarios.
} 


\subsection{Metric Definition}

The functional unit that forms the basis for the LCA is the generation of $1 \mathrm{kWh}$ of electricity by means of PV over 30 years. The functional unit metric is therefore defined as the total life cycle environmental impact of the PV system divided by the total amount of electricity produced by the system over 30 years (see Equation 1). The lower the metric value is, the more favourable it is for the environment.

For this analysis, a time horizon of 30 years is considered. If a PV panel is used for 30 years, then only one product cycle is needed in 30 years. If a panel is used for 15 years before being replaced by a new panel, two product cycles are required, and three product cycles are required when replacements occur every 10 years (Table 1; see Equation 2). In each product cycle, the peak power of the panel increases owing to technological innovation (see Equation 3 ). The lifetime of an inverter is assumed to be 15 years (10). For a 30-year period, two inverters are required (see Equation 4).

\section{Table 1: Number of product cycles in $\mathbf{3 0}$ years}

\begin{tabular}{|l|l|l|}
$\begin{array}{l}\text { Service life of a panel } \\
\text { (years) }\end{array}$ & $\begin{array}{l}\text { Number of product cycles } \\
\text { in } 30 \text { years for panels and in } 30 \text { years for inverters (z) } \\
\text { BOS (excluding inverters) } \\
(\mathrm{n})\end{array}$ & $\begin{array}{c}\text { Number of product cycles } \\
\text { invers }\end{array}$ \\
\hline 10 & 3 & $\mathbf{2}$ \\
\hline 15 & 2 & 2 \\
\hline 30 & 1 & 2 \\
\hline
\end{tabular}

For a single service life of a PV system, the metric can be written as:

$$
\frac{E I(P)+E I(I)+E I(B O S)}{\sum_{t=1}^{N}\left(\text { Yield } \times P_{t}\right)}
$$

where,
$t$
Time [years]
$N$
Service lifetime of the panels in one cycle as defined in Table 1
$E I(P)$
Environmental impact of the panel over its life cycle [unit of the impact category]
El(I) Environmental impact of the inverter over its life cycle [unit of the impact category]
El(BOS) Environmental impact of the BOS, excluding inverter, over its life cycle [unit of the impact category]
Yield Initial system yield [kWh/kWp/year]
$\mathrm{P}_{\mathrm{t}} \quad$ Peak power of the panel [kWp] - function of time due to degradation 
This exercise looks at different scenarios, each covering a total life span of 30 years. The cumulative environmental impact per functional unit can be calculated as the total environmental impact of the PV system over 30 years divided by the total output electricity generated over 30 years. To cover the 30-year period, one, two, or three cycles occur depending on the service life of the panels $(30,15$, or 10 years).

The metric, or the cumulative environmental impact per functional unit, can be written as:

$$
\frac{\sum_{i=1}^{n}\left(E I(P)_{i}+E I(B O S)_{i}\right)+\sum_{i=1}^{z} E I(I)_{i}}{\sum_{i=1}^{n} \sum_{t=1}^{N}\left(\text { Yield } \times P_{t, i}\right)}
$$

where
$t$
Time [years]
N
Service lifetime of the panels in one cycle as defined in Table 1
$n$
Number of product cycles in 30 years for PV panel and BOS
$z$
Number of product cycles in 30 years for the inverter
i
Cycle number
$E I(P) \quad$ Environmental impact of the panel over its life cycle [unit of the impact category]
EI(I) Environmental impact of the inverter over its life cycle [unit of the impact category]
EI(BOS) Environmental impact of the BOS, excluding inverter, over its life cycle [unit of the impact category]
Yield Initial system yield [kWh/kWp/year]
$\mathrm{P}_{\mathrm{t}, \mathrm{i}} \quad$ Peak power of the panel [kWp] - function of time due to degradation and of the cycle

The denominator of Equation 2 represents the electricity production of the system over 30 years. The annual electricity production of a PV panel decreases over time owing to field degradation. Although the degradation is exponential, the degradation curve is approximately linear because of the low degradation rate. Therefore, to simplify the calculation, a linear degradation curve is used. Panel peak power $\mathrm{P}$ is a function of $t$ due to degradation and a function of i due to improvement in panel efficiency (see Equation 3). 
The total electricity generated by a panel over its lifetime is calculated using the following equation:

Where,

$$
\sum_{i=1}^{n}\left[\text { Yield } \times P_{1} \times(1+a)^{(N \times(i-1))} \times\left(1-r \times \frac{N}{2}\right) \times N\right]
$$

$$
\begin{array}{ll}
N & \text { Service lifetime of the panels in one cycle as defined in Table } 1 \\
n & \text { Number of product cycles in } 30 \text { years for } \mathrm{PV} \text { panel and BOS } \\
i & \text { Cycle number } \\
\text { Yield } & \text { Initial system yield [kWh/kWp/year] } \\
\mathrm{P}_{1} & \text { Peak power of the panel in year } 1 \text { of the } 30 \text {-year period [kWp] } \\
\mathrm{a} & \text { Yearly projected power rate improvement [\%] } \\
r & \text { Degradation rate [\%] }
\end{array}
$$

The numerator of Equation 2 represents the environmental impact of the system over a 30year life. The numerator can be written out as presented in Equation 4. Environmental impact El may be a function of $i$, due to technology improvement in panel production and recycling processes. This assumption is tested by means of a sensitivity assessment. In the base case calculations, no technology improvement is assumed, the parameter "b" equals 0 . In the sensitivity assessment, the effect of a decreasing environmental impact (in steps of 5 years) is tested.

$$
\sum_{i=1}^{n}\left[(E I(P)+E I(B O S)) \times(1-b)^{\frac{N}{5} \times(i-1)}\right]+\sum_{i=1}^{z}\left[\left(E I(I) \times(1-b)^{\frac{N}{5} \times(i-1)}\right]\right.
$$

Where,
$n$
Number of product cycles in 30 years for PV panel and BOS
$z$
Number of product cycles in 30 years for inverters
i
Cycle number
$E I(P)$
Environmental impact of the panel over its life cycle [unit of the impact category]
EI(I) Environmental impact of the inverter over its life cycle [unit of the impact category]
El(BOS) Environmental impact of the BOS, excluding inverter, over its life cycle [unit of the impact category]
b 5-yearly projected environmental improvement rate [\%]
$\mathrm{N}$
Service lifetime of the panels in one cycle as defined in Table 1

Table 2 provides the input parameters used in this assessment for electricity production calculations by means of Equation 3.

Table 2: Summary of input parameters for electricity production calculations 


\begin{tabular}{|c|c|c|c|}
\hline Parameter & Value & Unit & Reference \\
\hline Average yield at optimal angle (yield) & 1.090 & $\mathrm{kWh} / \mathrm{kWp}$ & PEFCR (1) \\
\hline Degradation rate (r) & 0,7 & $\% /$ year & PEFCR (1) \\
\hline Peak power at year $1\left(P_{1}\right)$ & 235,2 & Wp/panel & PEFCR (1) \\
\hline $\begin{array}{l}\text { Projected rate of improvement for output } \\
\text { power (a) }\end{array}$ & 1,4 & $\% /$ year & $\begin{array}{l}\text { Derived from ITRPV forecast 2018- } \\
2029 \text { (9) }\end{array}$ \\
\hline Technical lifetime & 30 & years & PEFCR (1) \\
\hline Service lifetime (N) & $\begin{array}{l}10,15 \\
\text { or } 30\end{array}$ & years & See Table 1 \\
\hline $\begin{array}{l}\text { 5-yearly projected environmental } \\
\text { improvement rate }\end{array}$ & $\begin{array}{l}0 \\
10\end{array}$ & $\%$ & $\begin{array}{l}\text { Base case } \\
\text { Assumption used in sensitivity } \\
\text { assessment }\end{array}$ \\
\hline
\end{tabular}

The total electricity production calculated using Equation 3 for a period of 30 years with different panel service lifetimes is shown in Table 3.

Table 3: Total electricity production for a period of 30 years with different panel service lifetimes; second and third lifetimes consider new panels with improved performance compared to the first cycle's panel

\begin{tabular}{|ccccc|}
$\begin{array}{c}\text { Panel } \\
\text { service } \\
\text { lifetime } \\
\text { (years) }\end{array}$ & $\begin{array}{c}\text { Total electricity } \\
\text { produced in the } \\
\text { first cycle (kWh) }\end{array}$ & $\begin{array}{c}\text { Total electricity } \\
\text { produced in the } \\
\text { second cycle } \\
\text { (kWh) }\end{array}$ & $\begin{array}{c}\text { Total electricity } \\
\text { produced in the } \\
\text { third cycle } \\
\text { (kWh) }\end{array}$ & $\begin{array}{c}\text { Total electricity } \\
\text { produced in } 30 \\
\text { years (kWh) }\end{array}$ \\
\hline $\mathbf{1 0}$ & 2.474 & 2.843 & 3.267 & 8.584 \\
\hline $\mathbf{1 5}$ & 3.644 & 4.489 & $/$ & 8.132 \\
\hline $\mathbf{3 0}$ & 6.883 & 1 & $/$ & 6.883 \\
\hline
\end{tabular}




\section{LIFE CYCLE ASSESSMENT MODELLING}

\subsection{Life Cycle Inventory}

The life cycle inventory (LCI) phase of this LCA entails gathering data to analyse the environmental impacts associated with production, transport, EOL treatment, and-for the sensitivity assessment-use of the PV system.

\subsubsection{LCI for producing the multi-crystalline silicon panel and BOS for flat roof- mounted systems}

The $\mathrm{LCl}$ for producing the multi-crystalline silicon panel is from the Product Environmental Footprint (PEF) Excel file with data inventory: "PEFCR_PV_electricity_v0.20 - Life cycle inventory." The file is available for download from the European Commission's website (11). The data were inserted in SimaPro using the ecoinvent 3.6 database (cut-off version). In the "cut-off" (also known as "recycled content") approach, the first production of materials is allocated to the primary user of a material. If a material is recycled, the primary producer does not receive any credit for the provision of any recyclable materials. In this approach, recyclable materials are available burden-free to recycling processes, and recycled materials only bear the impacts of the recycling processes (12). To insert the data in SimaPro, we started from the existing ecoinvent record "Photovoltaic panel, multi-Si wafer $\{$ RER $\} \mid$ production | Cut-off, U" (RER stands for Europe). This existing ecoinvent $\mathrm{LCl}$ dataset was adapted as much as possible to the LCl dataset for "Photovoltaic panel, multi-Si, at regional storage" available in PEF. Contrary to the PEF method, where PEF-compliant datasets were required, in this study ecoinvent datasets were always used.

The silicon type used in the assessment is a casted multi-crystalline silicon. To produce $1 \mathrm{~kg}$ of this material, $0,198 \mathrm{~kg}$ of electronic-grade silicon and $0,802 \mathrm{~kg}$ of solar-grade silicon are used. The aluminium frame is modelled with an aluminium alloy consisting of $26 \%$ primary and $74 \%$ secondary aluminium.

To account for the distribution and storage of PV panels produced, the data record "Photovoltaic panel, multi-Si, at regional storage" was created. This data record accounts for PV panel manufacturing in China, Asia \& Pacific (APAC), and Europe, plus the associated transport of panels by lorry and ship. For $1 \mathrm{~m}^{2}$ of multi-crystalline silicon PV panel with regional storage, $0,145 \mathrm{~m}^{2}$ are manufactured in Europe, $0,798 \mathrm{~m}^{2}$ are manufactured in China, and $0,058 \mathrm{~m}^{2}$ are manufactured in the APAC region. 
Table 4 shows the inventory for the panel manufactured in Europe, modified according to the PEF datasets. The difference between manufacturing in Europe, China, and the APAC region is the electricity and/or heat consumption in the supply chain for the different regions. The inventory for the other regions can be accessed from the Product Environmental Footprint Category Rules (PEFCR) (1). 
Table 4: LCl of multi-crystalline silicon PV panel (60-cell, $1,6 \mathrm{~m}^{2}, 13,2 \mathrm{~kg}$ with a peak power of 235,2 Wh/panel); the ecoinvent record "Photovoltaic panel, multi-Si wafer \{RER\} | production | Cut-off, U” was modified to better align with the PEF LCI

\begin{tabular}{|c|c|c|c|}
\hline & Name of ecoinvent record & Unit & Amount \\
\hline $\begin{array}{l}\text { Product } \\
\text { (output) }\end{array}$ & Photovoltaic panel, multi-Si wafer (RER), production & $\mathrm{m}^{2}$ & 1 \\
\hline \multirow[t]{25}{*}{ Inputs } & 1-propanol $\{G L O\} \mid$ market for | Cut-off, U & $\mathrm{kg}$ & 0,0159 \\
\hline & Acetone, liquid $\{R E R\} \mid$ market for acetone, liquid | Cut-off, $U$ & $\mathrm{~kg}$ & 0 \\
\hline & Aluminium alloy, AIMg3 $\{$ GLO\}| market for | Cut-off, $U$ & $\mathrm{kg}$ & 2,13 \\
\hline & Brazing solder, cadmium free $\{$ GLO\}| market for | Cut-off, $U$ & $\mathrm{kg}$ & 0 \\
\hline & Copper $\{$ GLO\}| market for | Cut-off, U & $\mathrm{kg}$ & 0,103 \\
\hline & Corrugated board box $\{$ RER $\} \mid$ market for corrugated board box | Cut-off, $U$ & $\mathrm{~kg}$ & 0,763 \\
\hline & EUR-flat pallet $\{G L O\} \mid$ market for | Cut-off, U & $\mathrm{p}$ & 0,05 \\
\hline & Diesel \{Europe without Switzerland\}| market for | Cut-off, U & $\mathrm{kg}$ & 0,00933 \\
\hline & Diode, glass-, for surface-mounting $\{$ GLO\}| market for | Cut-off, $U$ & $\mathrm{kg}$ & 0,002808 \\
\hline & Electricity, medium voltage $\{R E R\} \mid$ market group for | Cut-off, $U$ & MJ & 13,4 \\
\hline & Ethylvinylacetate, foil $\{G L O\} \mid$ market for | Cut-off, U & $\mathrm{kg}$ & 0,875 \\
\hline & $\begin{array}{l}\text { Glass fibre reinforced plastic, polyamide, injection moulded }\{G L O\} \mid \text { market } \\
\text { for | Cut-off, } U\end{array}$ & $\mathrm{~kg}$ & 0,295 \\
\hline & Heat, district or industrial, natural gas $\{R E R\} \mid$ market group for | Cut-off, $U$ & MJ & 0 \\
\hline & Hydrogen fluoride $\{R E R\} \mid$ market for hydrogen fluoride | Cut-off, $U$ & $\mathrm{~kg}$ & 0,0624 \\
\hline & Polyethylene, high density, granulate $\{$ GLO $\} \mid$ market for | Cut-off, U & $\mathrm{kg}$ & 0,0238 \\
\hline & Isopropanol \{RER\}| market for isopropanol | Cut-off, U & $\mathrm{kg}$ & 0,000147 \\
\hline & Lead $\{$ GLO\}| market for | Cut-off, U & $\mathrm{kg}$ & 0,000725 \\
\hline & Lubricating oil $\{R E R\} \mid$ market for lubricating oil | Cut-off, U & $\mathrm{kg}$ & 0 \\
\hline & Methanol $\{$ GLO\}| market for | Cut-off, U & $\mathrm{kg}$ & 0 \\
\hline & Nickel, 99.5\% \{GLO\}| market for | Cut-off, U & $\mathrm{kg}$ & 0 \\
\hline & $\begin{array}{l}\text { Photovoltaic cell, multi-Si wafer }\{\text { RER }\} \mid \text { production | Cut-off, U- } \\
\text { Circusol_updated }\end{array}$ & $\mathrm{m} 2$ & 0,935 \\
\hline & Photovoltaic panel factory $\{\mathrm{GLO}\} \mid$ market for | Cut-off, U & $p$ & 0,000004 \\
\hline & $\begin{array}{l}\text { Polyethylene terephthalate, granulate, amorphous }\{G L O\} \mid \text { market for | Cut- } \\
\text { off, U }\end{array}$ & $\mathrm{kg}$ & 0,346 \\
\hline & Polyvinylfluoride, film \{GLO\}| market for | Cut-off, U & $\mathrm{kg}$ & 0,112 \\
\hline & Potassium hydroxide $\{$ GLO\}| market for | Cut-off, U & $\mathrm{kg}$ & 0,0514 \\
\hline
\end{tabular}




\begin{tabular}{|lcc|}
\hline Name of ecoinvent record & Unit & Amount \\
\hline Silicone product $\{$ RER\}| market for silicone product | Cut-off, U & kg & 0,12195 \\
\hline Soap $\{$ GLO\}| market for | Cut-off, U & $\mathrm{kg}$ & 0,0116 \\
\hline Solar glass, low-iron $\{$ GLO\}| market for | Cut-off, U & $\mathrm{kg}$ & 8,81 \\
\hline Tap water $\{$ RER\}| market group for | Cut-off, U & $\mathrm{kg}$ & 5,03 \\
\hline Tempering, flat glass $\{$ GLO\}| market for | Cut-off, U & $\mathrm{kg}$ & 8,81 \\
\hline Tin $\{$ GLO\}| market for | Cut-off, U & $\mathrm{kg}$ & 0,0129 \\
\hline Vinyl acetate $\{$ GLO\}| market for | Cut-off, U & $\mathrm{kg}$ & 0 \\
\hline Wire drawing, copper $\{$ GLO\}| market for | Cut-off, U & $\mathrm{kg}$ & 0,103 \\
\hline Transport, freight train $\{$ GLO\}| market group for | Cut-off, U & $\mathrm{kgkm}$ & 42.500 \\
\hline Transport, freight, lorry $>32$ metric ton, EURO4 $\{$ RER\}| market for transport, & $\mathrm{kgkm}$ & 5.850 \\
\hline freight, lorry $>32$ metric ton, EURO4 | Cut-off, U & \\
\hline
\end{tabular}

The following abbreviations are used in ecoinvent records mentioned in the table: RER (Representative European Region), GLO (global data), U (unit process), EURO4 (European emissions standard).

The BOS consists of an inverter, electric installation (fuse box, cabling, and grounding wires), and mounting system (including all material and packaging for clamps, support, and rails). The inventory for the inverter is from a recent publication by Tschümperlin et al. (10) and was inserted in SimaPro using ecoinvent 3.6 datasets. One 2,5-kW inverter is needed for $20,6 \mathrm{~m}^{2}$ of panels. For the electric installation, the ecoinvent record "Photovoltaic plant, electric installation for $3 \mathrm{kWp}$ module $\{\mathrm{CH}\} \mid$ photovoltaics, electric installation for $3 \mathrm{kWp}$ module, at building | Cut-off, U" is used. Finally, the mounting system is modelled with the ecoinvent record, "Photovoltaic mounting system, for flat-roof installation $\{R E R\} \mid$ production | Cut-off, U."

\subsubsection{LCl for recycling multi-crystalline silicon panel, inverter, and mounting system}

The data for recycling the multi-crystalline silicon panel are from an IEA Task 12 publication on recycling of panels (13). The recycled content or cut-off approach is used for modelling this life cycle phase. When applying the cut-off approach, the total efforts of panel recycling are allocated to the co-products, waste treatment, and recovery of glass cullet, aluminium scrap, and copper scrap using the economic (price-based) allocation factors mentioned in a Task 12 publication (13). This study takes into account the impacts allocated to the waste treatment process by including the electricity, transport, and diesel fuel needed for treating the panels. For the mounting structure and other parts of the BOS, ecoinvent cut-off records are used, which take EOL recycling into account according to the cut-off approach.

\subsection{3 $\mathrm{LCl}$ for sensitivity assessment of repair activities}

In addition to the baseline scenario, in which panels are kept in use with no need for repair or additional transport throughout their 30-year service lifetime, repair activities and/or additional transport are added in sensitivity assessments.

Junction box failures were identified as suitable candidate failures for repair based on Tsanakas et al (7). Replacement of a junction box entails the production of a new junction box. 
Data on possible energy use during replacement of the junction box were not available and were omitted because this energy use is likely negligible. Also, the possible impact of testing the panels, which might occur before or after panel repair, was not considered owing to lack of data. The repair activity is limited to production of a new junction box. The inventory used to model this production is shown in Table 5.

Table 5: LCl data for junction box production (amount necessary per $\mathrm{m}^{2}$ of $\mathrm{PV}$ panel)

\begin{tabular}{|c|c|c|c|}
\hline Name & Name (ecoinvent) record & Uni & Amoun \\
\hline $\begin{array}{l}\text { Product } \\
\text { (output) }\end{array}$ & Junction box & $\mathbf{m}^{2}$ & 1 \\
\hline \multirow[t]{5}{*}{ Inputs } & $\begin{array}{l}\text { Diode, glass-, for surface-mounting }\{\text { GLO }\} \mid \text { market for | } \\
\text { Cut-off, } U\end{array}$ & $\mathrm{~kg}$ & 0,00281 \\
\hline & $\begin{array}{l}\text { Polyethylene, high density, granulate }\{\text { GLO }\} \mid \text { market for } \\
\text { | Cut-off, } U\end{array}$ & $\mathrm{~kg}$ & 0,0238 \\
\hline & $\begin{array}{l}\text { Glass fibre reinforced plastic, polyamide, injection } \\
\text { moulded }\{G L O\} \mid \text { market for | Cut-off, } U\end{array}$ & $\mathrm{~kg}$ & 0,295 \\
\hline & Injection moulding $\{R E R\} \mid$ processing| Cut-off, $U$ & $\mathrm{~kg}$ & 0,0238 \\
\hline & Cable, unspecified $\{G L O\} \mid$ production | Cut-off, $U$ & $\mathrm{~kg}$ & 0,12 \\
\hline
\end{tabular}

\subsubsection{LCl for sensitivity assessment of transporting multi-crystalline silicon panel to new installation site}

The impact of transporting panels to another installation site (for further use until the end of the 30-year technical lifetime) is investigated in another sensitivity assessment. It is unknown what type of transport mode is mostly used to transport panels from one installation site to another. This analysis assumes the panels are transported with a van. The distance is varied from $100 \mathrm{~km}$ and $10.000 \mathrm{~km}$ to understand the impact of transport. The LCl of transportation with a van is from the ecoinvent 3.6 database (record: Transport, freight, light commercial vehicle $\{R E R\} \mid$ market group for transport, freight, light commercial vehicle | Cut-off, U).

\subsection{Life Cycle Impact Assessment}

The inventory data from Section 3.1 are used to conduct a life cycle impact assessment (LCIA). Several LCIA methods exist. The PEF, developed by the EU (14), assesses the overall environmental impacts of a product. The PEF environmental impact assessment method, called Environmental Footprint (EF) method 3.0 (EF method), includes 16 indicators that quantify impacts on air, water, and soil quality, the climate, and resource depletion. In our study, this EF method 3.0 is used for the LCIA. SimaPro software (15) is used for the calculations. This software contains an EF 3.0 method that corresponds to the flows used in the ecoinvent 3.6 database (16).

Full results (all impact categories at midpoint level) for panel $\left(1,6 \mathrm{~m}^{2}\right.$ and $13,2 \mathrm{~kg}$ ), inverter, and BOS (excluding the inverter and PV mounting system) production and recycling (according to the cut-off approach) are listed in Annex A-1 and A-2. All impacts (single score and midpoint impacts) in Annex A-1 are shown relative to one panel. These results are not normalized by 
lifetime electricity production because-in the next report sections-the lifetime is varied to test the effect of early replacement and repair.

Panel manufacturing accounts for $61,5 \%$ of total single score impacts, followed by inverter production, which accounts for $21,7 \%$ of single score impacts. The BOS (excluding the inverter and mounting system), PV mounting system, and recycling of PV panels account for $10,6 \%$, $5,9 \%$, and $0,3 \%$ of the total single score impacts, respectively (Annex $A-1$ ).

In Annexes A-3 to A-12, we present results for scenario and sensitivity analyses at midpoint level for the following five impact categories:

- Climate change

- Resource use, minerals, and metals

- Resource use and energy carriers

- Respiratory inorganics

- Freshwater ecotoxicity

The first four impact categories were previously identified as the most relevant in the PV field (1). Freshwater ecotoxicity also contributes significantly to the life cycle impact of PV; this impact category has been identified as Level III (high degree of uncertainty) in the EF 3.0 method (17). The EF 3.0 method contains updated characterization factors for freshwater ecotoxicity. The method used for characterizing freshwater ecotoxicity is the USEtox2.1 method (18). Long-term emissions (emissions occurring beyond 100 years from today) are excluded.

The indicators are aggregated into a single score indicator through normalization and weighting $(17,19)$. The single score results (global single scores, with toxicity categories included) are shown in Figure 4. Single score results can serve as a common metric to analyse and compare scenarios and to support sound and effective decision making (20).

Using the LCl for the junction box in Table 5, the environmental impact per panel repair (junction box replacement) is calculated (see Annex A-2). The assumptions are described in Section 3.1. Annex A-2 also shows the environmental impact of transporting one panel weighing 13,2 $\mathrm{kg}$ for $1 \mathrm{~km}$ with a van. These figures are used to assess the influence of transporting panels between two use cycles, using transportation impact per panel for a distance of $100 \mathrm{~km}$ using a van and $10.000 \mathrm{~km}$ using a light commercial vehicle. 


\subsection{Definition of Study Cases}

When PV panels fail before reaching their expected 30 -year lifetime, it is important to understand the environmental impact of repair activities, to decide whether the panels should be repaired or sent for recycling, from an environmental perspective. In this study, the LCA method detailed above is systematically applied to a base case to analyse the environmental impact of lifetime extension. Figure 3 shows the base case scenarios as well as additional scenarios, which are described below.

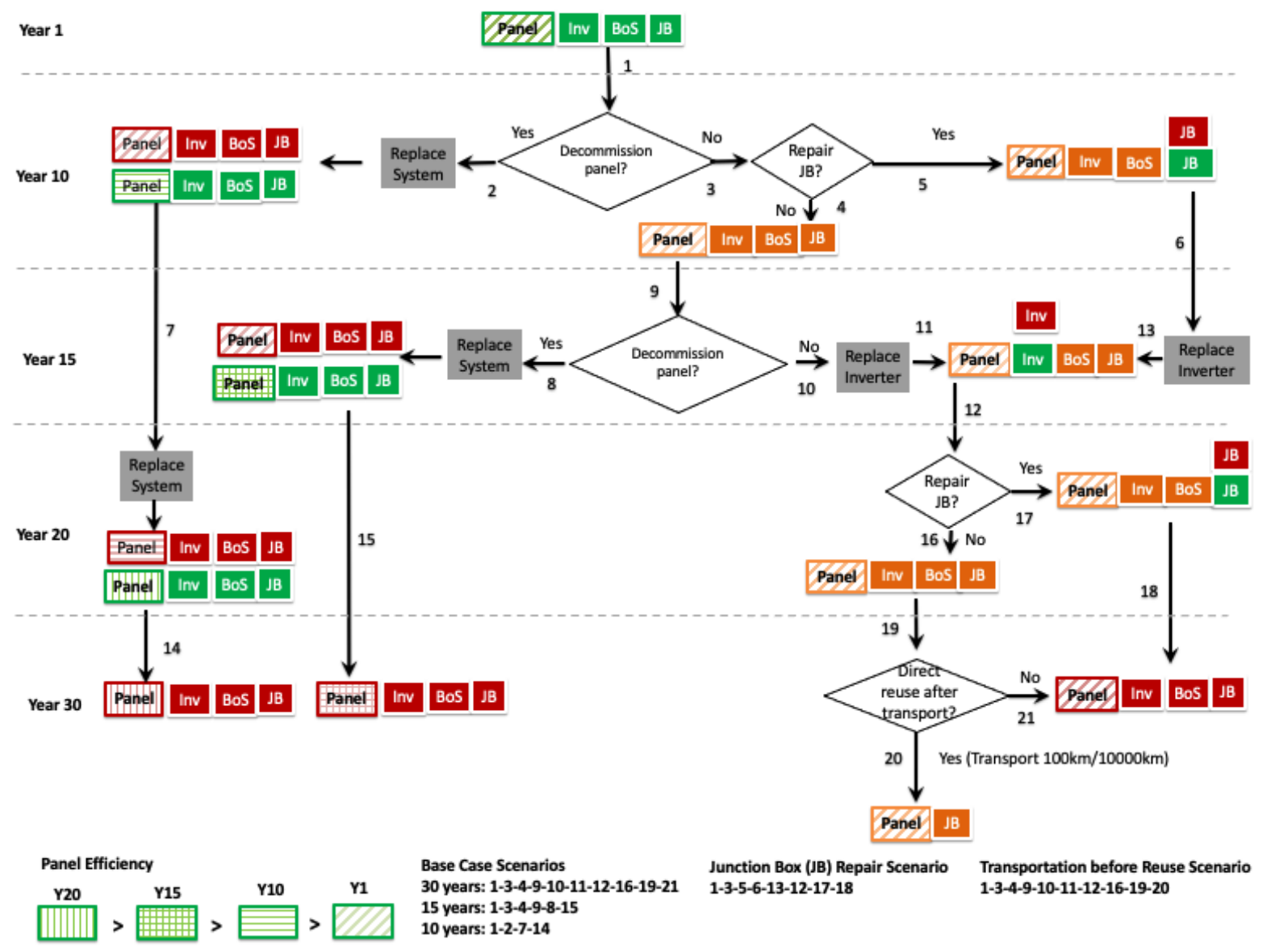

Figure 3: Scenarios used to quantify the economic and environmental impact of recycling, repair, and reuse of PV systems. The green boxes represent installation of a new PV system (panel+ inverter [Inv] + BOS + junction box [JB]). The orange boxes represent continued use of a previously installed PV system. The red boxes represent decommissioned PV systems, which are recycled. The decisions to recycle, repair, and reuse are made in years 10, 15, 20, and 30. The changing pattern in the "Panel" boxes represents an increase in panel efficiency over time.

In the base case scenarios, the impact of three PV service lifetimes over a 30-year timeframe are analysed:

- 30-year lifetime: The PV panel and BOS are used for 30 years, so the panel and BOS manufacturing and EOL recycling occur only once over the 30-year timeframe. The inverter is replaced every 15 years. 
- 15-year lifetime: The panel, inverter, and BOS are used for 15 years before being replaced by a new panel, inverter, and BOS. Therefore, two product cycles are required. The panel and BOS manufacturing and EOL recycling occur twice; the second time includes improved panel performance due to technological progress.

- 10-year lifetime: The panel, inverter, and BOS are used for 10 years before being replaced by a new panel, inverter, and BOS. Therefore, three product cycles are required. The panel and BOS manufacturing and EOL recycling occur three times; panel performance improves due to technological progress during the two replacements.

Based on these base case scenarios, three additional scenarios are modelled to quantify the impact of panel repair, reuse (including transportation), and technological improvements on the results:

- Repair: The repair scenario quantifies the sensitivity of the results to the repair of the junction box in years 10 and 20 over the 30 -year service lifetime. Junction box repair is used in the sensitivity analysis because junction box failure has been identified as a good candidate for repair (7).

- Transportation: For prematurely decommissioned panels, additional transport is likely needed to satisfy the service lifetime via direct reuse of the panels. This may include, for example, sending panels for repair and testing and/or to be installed at a different site. The distance and transport mode could vary. To indicate the significance of transport, two hypothetical and contrasting scenarios are modelled. One involves transport of one panel weighing 13,2 kg using a light commercial vehicle or van for 100 $\mathrm{km}$. The other involves transport of one panel weighing $13,2 \mathrm{~kg}$ with a light commercial vehicle for $10.000 \mathrm{~km}$.

- Technological improvements: Technology evolution (or revolution), including improvements to panel efficiency and the environmental footprint of production/recycling processes, will influence the results. The scenarios described above are based on the current projection for technological evolution. This sensitivity scenario accounts for potential revolutionary technological advances (Table 6).

Table 6: Technology evolution/revolution rates for panel performance and improvement in PV system environmental impact

\begin{tabular}{|c|c|c|}
\hline & $\begin{array}{c}\text { Improvement Rate of Panel Peak } \\
\text { Power }\end{array}$ & $\begin{array}{c}\text { Improvement Rate of PV System } \\
\text { Production/Recycling } \\
\text { Environmental Impact }\end{array}$ \\
\hline $\begin{array}{l}\text { Current } \\
\text { projection }\end{array}$ & $\begin{array}{l}\text { Peak power: }+1.4 \% \text { (annually) } \\
\text { Panel efficiency still below the Shockley- } \\
\text { Queisser limit in } 30 \text { years. }\end{array}$ & $0 \%$ \\
\hline $\begin{array}{l}\text { Hypothetical } \\
\text { projection } 1\end{array}$ & $\begin{array}{l}\text { Peak power: }+1.4 \% \text { (annually) } \\
\text { Panel efficiency still below the Shockley- } \\
\text { Queisser limit in } 30 \text { years. }\end{array}$ & $\begin{array}{l}10 \% \text { reduction every } 5 \text { years } \\
\text { (e.g., with higher energy efficiency in the } \\
\text { production process, less material used) }\end{array}$ \\
\hline $\begin{array}{l}\text { Hypothetical } \\
\text { projection } 2\end{array}$ & $\begin{array}{l}\text { Peak power: }+2.8 \% \text { (annually) } \\
\text { New technologies such as multijunction } \\
\text { cells become prevalent in the market. } \\
\text { Shockley-Queisser limit exceeded during } \\
\text { this } 30 \text {-year period. }\end{array}$ & $0 \%$ \\
\hline
\end{tabular}


Peak power: $+2.8 \%$ (annually)

Hypothetical

projection 3
New technologies such as multijunction

cells become prevalent in the market.

Shockley-Queisser limit exceeded during this 30 -year period.
$10 \%$ reduction every 5 years

(e.g., with higher energy efficiency in the production process, less material used) 


\section{RESULTS AND DISCUSSION}

\subsection{Base Case: Impact of Service Lifetime}

The full LCIA results for panel, inverter, and BOS production and recycling are listed in Annex A-1 and A-2. These results indicate that panel manufacturing accounts for $61,5 \%$ of total single score impacts, followed by inverter production at $21,7 \%$. The BOS (excluding the inverter and mounting system), mounting system, and panel recycling account for $10,6 \%, 5,9 \%$ and $0,3 \%$ of the total single score impacts, respectively.

Figure 4 compares environmental impacts per kWh produced over a 30-year period for the base case scenarios, showing that more frequent replacement of panels with newer (higherperformance) panels increases the environmental impact. In other words, it is better to keep panels in use until the end of their technical lifetimes, instead of replacing older panels with more efficient new ones. The efficiency gain does not offset the environmental footprint of additional panel production.

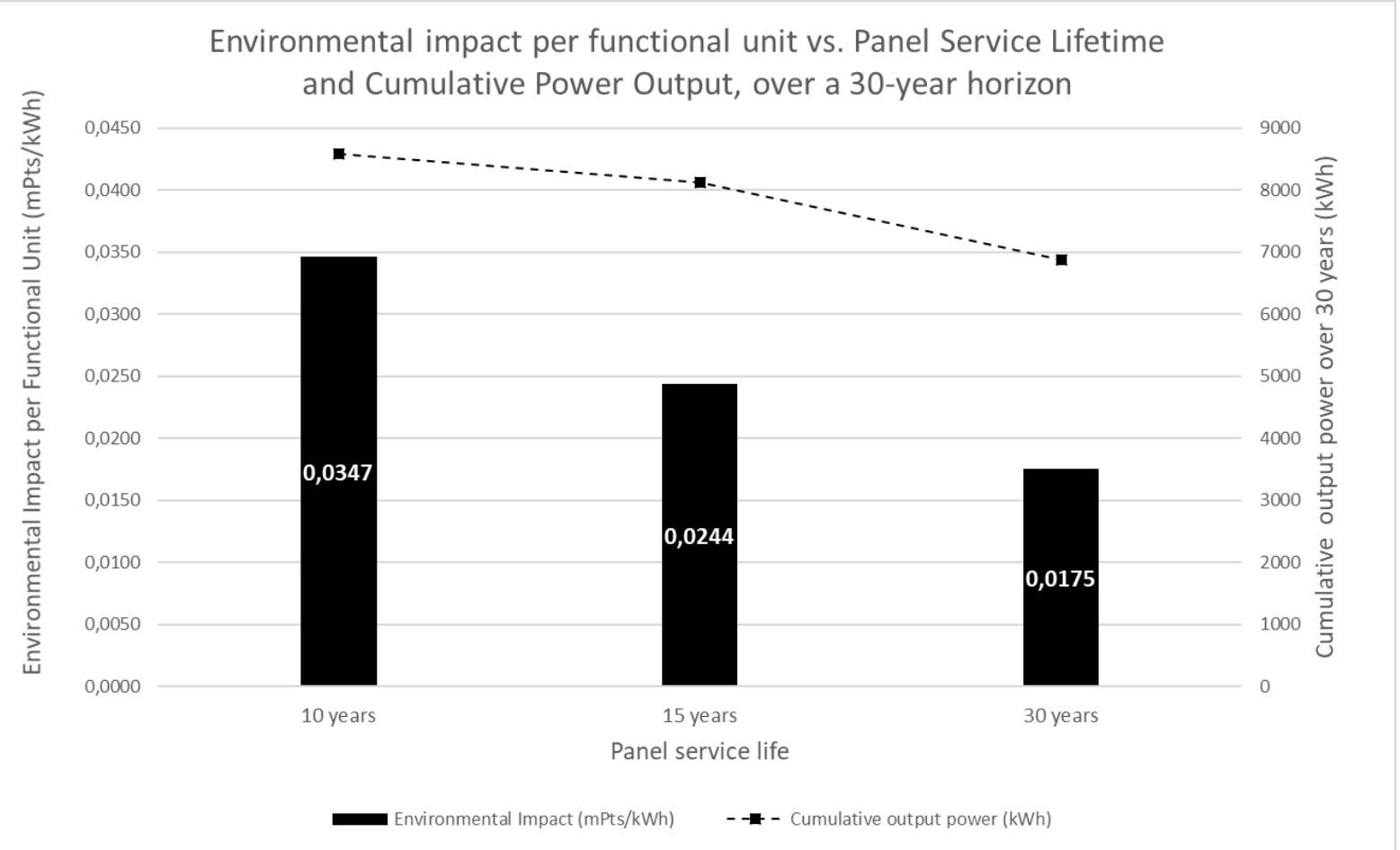

Figure 4: Environmental impact per functional unit of different panel service lifetimes, over a 30-year period. The environmental impact includes panel recycling at the end of each service lifetime. The figure represents the single score impacts in millipoints/kWh (mPts/kWh). PV technology: multi-crystalline silicon. System type: rooftop (flat roof). Panel efficiency rate: variable, increases $1,4 \%$ every year. Panel efficiency in the first cycle: $14,7 \%$. Degradation rate: $0,7 \%$. PV and BOS lifetime: variable, 10, 15, or 30 years. Inverter (part of BOS) lifetime: variable, 10 or 15 years. Installation location: Europe. Annual irradiation: $1.331 \mathrm{kWh} / \mathrm{m}^{2}$ (average for Europe). Performance ratio: $82 \%$ (excluding degradation). The midpoint impact results for the five categories contributing the most to the single score-climate change, respiratory inorganics, 
resource use (minerals and metals), resource use (energy carriers), and freshwater ecotoxicity-are presented in Annex A.

\subsection{Sensitivity Assessment: Impact of Junction Box Repair to Satisfy the Service Lifetime}

Figure 4 describes the basic scenario, in which a panel remains healthy throughout its technical lifetime and thus does not require repair to extend its lifetime (for the original owner) or to enable secondary use. In reality, however, repair activities likely will be needed to allow a panel to satisfy a service lifetime of 30 years. Figure 5 illustrates the environmental impact of such repair activities by assuming that junction box replacement is needed every 10 years (twice over a period of 30 years); the impact of the junction box replacements is almost negligible. Even if this repair is required twice, the environmental impact per kWh generated by a panel operated until the end of its 30 years lifetime is significantly lower compared to situations in which panels are replaced with more efficient panels every 10 or 15 years.

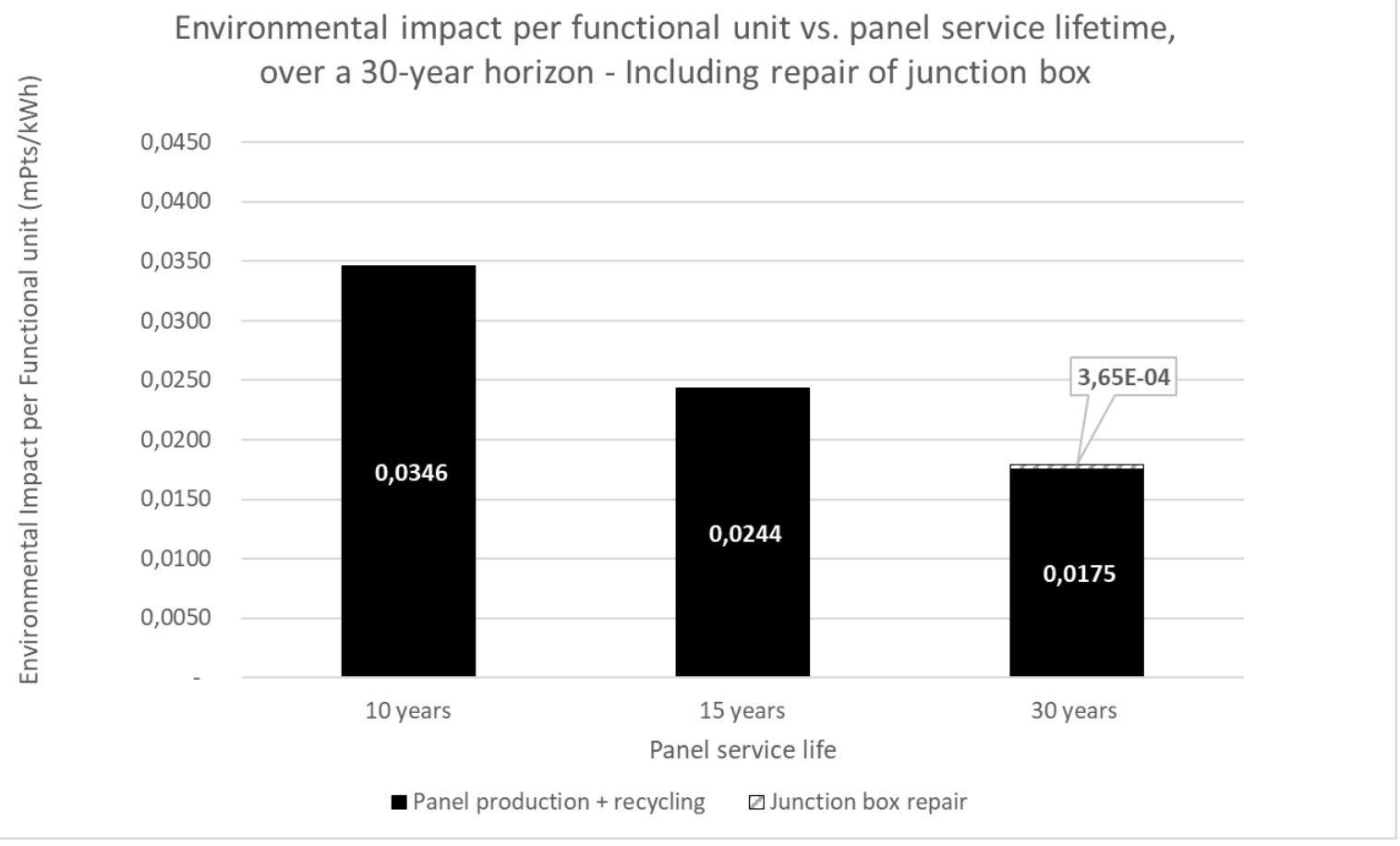

Figure 5: Additional environmental impact from repair activities (two replacements of junction box). PV technology: multi-crystalline silicon. System type: rooftop (flat roof). Panel efficiency rate: variable, increases $1,4 \%$ every year. Panel efficiency in the first cycle: $14,7 \%$. Degradation rate: $0,7 \%$. PV and BOS lifetime: variable, 10, 15 , or 30 years. Inverter (part of BOS) lifetime: variable, 10 or 15 years. Installation location: Europe. Annual irradiation: $1.331 \mathrm{kWh} / \mathrm{m}^{2}$ (average for Europe). Performance ratio: $82 \%$ (excluding degradation).

In this scenario, the environmental impact of panel production and recycling remains the same as in Figure 4, so Figure 5 shows the impact of junction box repair added to those results for the 30-year service lifetime. No repair is modelled for service lifetimes of 10 and 15 years; 
these follow the same trajectory of PV system manufacturing and recycling based on their cycle life (three cycles for 10-year service life, two cycles for 15-year service life).

Diode failure is also technically suitable for repair. Although such repair is not examined here owing to a lack of quality data, it is expected to have an even lower environmental impact.

\subsection{Sensitivity Assessment: Impact of Transportation Before Reuse to Satisfy the Service Lifetime}

Figure 6 shows the additional environmental impact caused by moving a panel to a new location to fulfil its service lifetime. Calculations are for two hypothetical transport distances: $100 \mathrm{~km}$ and $10.000 \mathrm{~km}$. Results show that, even under the extreme scenario-moving a panel $10.000 \mathrm{~km}$ in a light commercial vehicle to be reinstalled at a different location-the environmental benefit of satisfying the service lifetime still outweighs the additional environmental impact of the transport. Additional materials for a renewal of the BOS are not taken into account in this case.

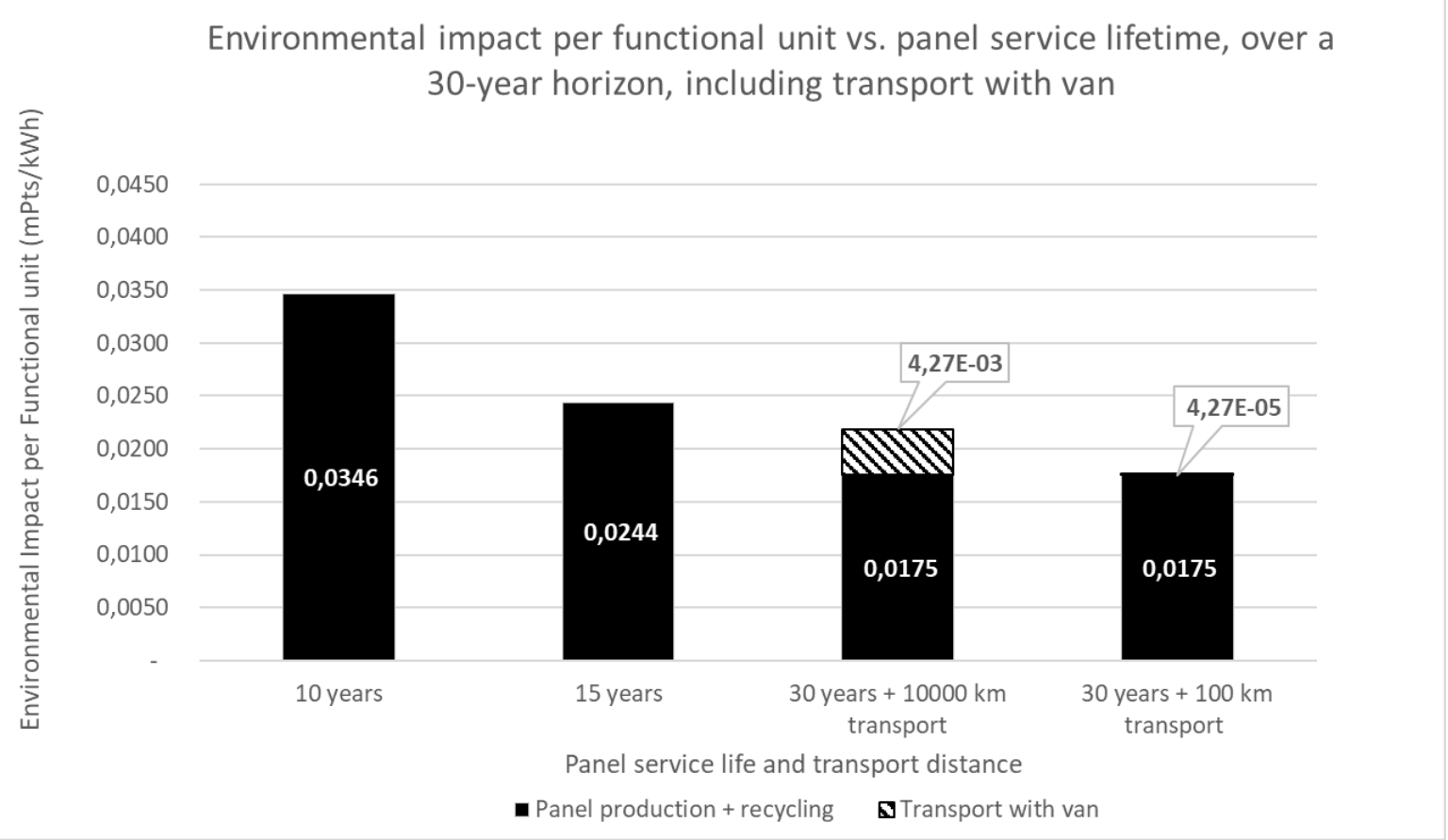

Figure 6: Environmental impact of panel transport for reuse in two extreme situations: transport for $10.000 \mathrm{~km}$ in a light commercial vehicle and $100 \mathrm{~km}$ in a van. PV technology: multi-crystalline silicon. System type: rooftop (flat roof). Panel efficiency rate: variable, increases $1,4 \%$ every year. Panel efficiency in the first cycle: $14,7 \%$. Degradation rate: $\mathbf{0 . 7 \%}$. PV and BOS lifetime: variable, 10, 15, or 30 years. Inverter (part of BOS) lifetime: variable, 10 or 15 years. Installation location: Europe. Annual irradiation: $1.331 \mathrm{kWh} / \mathrm{m}^{2}$ (average for Europe). Performance ratio: 82\% (excluding degradation). 


\subsection{Sensitivity Assessment: Impact of Technology Evolution/Revolution}

Figure 7 shows the environmental impact per functional unit for different combinations of technological improvement rates plotted against different panel service lifetimes. The environmental impact per functional unit is always lower with a longer panel service lifetime. Even a drastic technological change is unlikely to make replacing older panels with new ones an environmentally favourable choice. In Annex A, the results are presented at midpoint level for five separate impact categories, previously identified as the most relevant in the PV field: climate change, resource use (energy carriers), resource use (minerals and metals), respiratory inorganics, and freshwater ecotoxicity. The conclusion remains the same for all five of these impact categories.

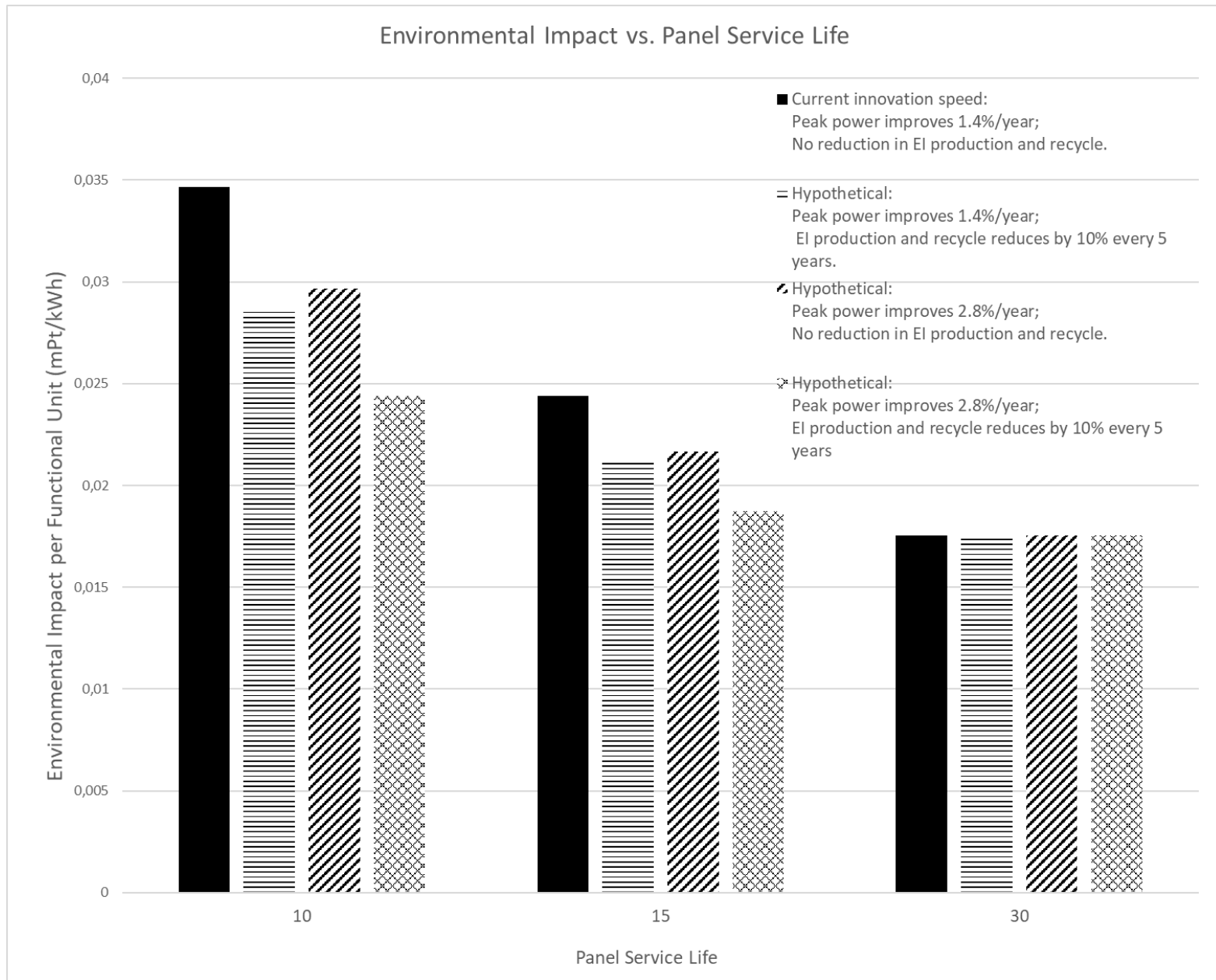

Figure 7: Environmental impact (EI) per functional unit versus different panel service lifetimes $(10,15$, and 30 years), with different technology projections for improvement in peak power and panel environmental impact reduction in manufacturing and recycling. 


\section{CONCLUSIONS}

The goal of this study was to build preliminary knowledge about the possibilities and limitations of keeping PV panels in use through a 30-year service lifetime, rather than recycling them and replacing them with new, more efficient panels before that service lifetime is reached. Our analyses satisfy the 30-year lifetime of prematurely decommissioned panels through two pathways: with interventions to the panel (e.g., repair before reuse) or without interventions (transportation and direct reuse). Part A of the study, detailed above, focuses on environmental impacts, which are discussed here. Part $B$, starting below, focuses on financial impacts.

Our LCA results show that satisfying the 30-year service lifetime of PV panels is clearly favourable from an environmental perspective. Replacing panels earlier (every 10 years or after 15 years) results in a higher environmental impact per kWh of electricity produced, which is not fully offset by the environmental benefits of recycling the removed panel or the higher yield of the new panels. Moreover, our sensitivity assessment shows that, even if maintaining the 30-year service life requires junction box repair and/or transporting the panel for long distances, keeping panels in use is the more environmentally favourable solution. In other words, it is better for the environment to keep a panel in use for 30 years instead of replacing it with new, more efficient panels. This conclusion does not appear to change even with a revolution in panel efficiency (doubling of the annual rate of peak power increase) and/or higher process efficiencies in manufacturing and recycling $(10 \%$ decrease in environmental impacts every 5 years).

Our analysis uses a constant system-specific panel yield. In reality, fulfilling the 30-year service life of panels may involve changing geographical location and hence changing performance ratio. It would be interesting to investigate the sensitivity of the results to this factor in future work. In general, little is known about the amounts, characteristics, and fates of earlydecommissioned PV panels. Decommissioned panels likely will proliferate in the future, so it would be useful to collect more data on product and waste streams and to investigate further the environmental impacts of different EOL treatment options.

Our LCAs in this study use the EU as the broad geographical area for background data. The EOL options align with regulations in the EU, where landfilling is not a valid option and recycling is the default pathway. However, where no regulations exist for electronic waste management and landfilling of panels might be the preferred disposal route, the study's conclusions might not be valid.

In addition, our study only examines multi-crystalline silicon PV, which limits the validity of the quantitative results to this technology. The method applied is, however, valid for other commercial PV technologies and can be used as a framework for future work on new PV technologies. The message about the environmental benefits of keeping panels in use for a long service life is not expected to change for other PV technologies. The sensitivity assessments in this study tend to support this hypothesis.

Apart from the environmental benefits of a long PV-use phase, there might be other arguments for lifetime extension and reuse of PV installations, such as social desirability or desirability from a policy perspective. These aspects are not considered in this study; it would be interesting to see how they affect our conclusions. 
PART B

FINANCIAL VIABILITY ANALYSIS OF SATISFYING THE LIFETIME OF PREMATURELY DECOMMISSIONED PV PANELS 


\section{RESEARCH QUESTIONS}

To generate a successful business case for satisfying the lifetime of PV panels, financial incentives must be quantified for the supply and demand sides of using the prematurely decommissioned PV panels for 30 years. In this report, the demand side represents parties aiming to install PV panels, while the supply side has prematurely decommissioned panels to offer (e.g., due to repowering). The following are the main research questions for this part of the report:

- On the demand side, when is it financially more attractive to reuse a prematurely decommissioned PV panel rather than purchase a new panel, and what is the maximum willingness to pay (WTP) for the prematurely decommissioned panel?

- On the supply side, when is it financially more attractive to send a prematurely decommissioned PV panel for reuse rather than recycling, and what is the minimum price to be charged for a prematurely decommissioned panel?

- Is the WTP for satisfying the lifetime of the prematurely decommissioned PV panel on the demand side through reuse higher than the determined minimum price on the supply side?

The business case for the prematurely decommissioned PV panel is only financially viable if the answer to the last question is affirmative. The following is one final question:

- How financially attractive is it to satisfy the lifetime of a prematurely decommissioned PV panel through reuse in real-life cases? 


\section{METHODOLOGY AND RESULTS}

For the scope of the following generic analysis, a ground-mount, utility-scale PV system with 60 -cell, multi-crystalline silicon panels is considered. The system is assumed to be located in Europe, where the average specific yield at optimal angle is $1.090 \mathrm{kWh} / \mathrm{kWp}(1)$. The business case described is generalized and indicative. The analysis should not serve as a decisionmaking tool.

\subsection{Levelized Cost of Energy}

Levelized cost of energy (LCOE) is the financial key performance indicator (KPI) for this generic analysis. LCOE is a widely used metric for comparing different energy solutions, because it represents the average net present cost of electricity generated from an energy source over its lifetime. It is calculated as all the discounted costs over the lifetime of an electricity generation installation or plant, divided by the sum of the actual energy amounts delivered.

LCOE mainly serves as a societal cost metric, but LCOE analyses can also be applied in specific use cases that focus on self-consumption of electricity from PV (see Section 3.1).

PV LCOE is expressed in $€ / \mathrm{kWh}$ and can be further specified as follows:

$$
L C O E=\frac{C A P E X(P V)+C A P E X(B O S)+O P E X}{\text { Total electricity production }}
$$

Where
CAPEX $(P V)$
All capital expenses related to the PV panels [€]
CAPEX(BOS)
All capital expenses related to the BOS [€]
OPEX
Discounted sum of operational expenses over the lifetime of the installation (PV + BOS) [€]

Total electricity Sum of the electricity produced over the lifetime of the installation production [kWh]

The BOS encompasses all components of the PV system other than the panels and junction boxes. The BOS includes wiring, switches, the mounting system, and inverters.

When normalized to $\mathrm{kWp}$, LCOE can be rewritten as (derived from (21)):

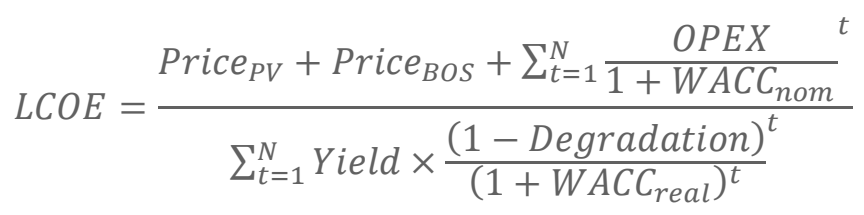

Where
$t$
Time [years]
$N \quad$ Economic lifetime of the system [years]
Price $_{P V} \quad$ CAPEX for the PV panels at $\mathrm{t}=0[€ / \mathrm{kWp}]$ 


\begin{tabular}{|c|c|}
\hline Price $_{B O S}$ & CAPEX for the BOS at $\mathrm{t}=0[€ / \mathrm{kWp}]$ \\
\hline$P E X$ & $\begin{array}{l}\text { OPEX made for the system, mainly operations and maintenance } \\
{[€ / \text { year/kWp] }}\end{array}$ \\
\hline ield & Initial system yield [kWh/kWp/year] \\
\hline egradation & Yearly degradation rate of the PV panels [\%] \\
\hline$A C C_{n o m}$ & $\begin{array}{l}\text { Nominal weighted average cost of capital, taking into account } \\
\text { inflation [\%] }\end{array}$ \\
\hline$A C C_{\text {real }}$ & $\begin{array}{l}\text { Real weighted average cost of capital, not taking into account } \\
\text { inflation [\%] }\end{array}$ \\
\hline
\end{tabular}

\subsection{Demand Side: Willingness to Pay for Prematurely Decommissioned PV}

LCOE parity is used to determine the financial viability of satisfying the lifetime of the prematurely decommissioned PV through reuse. On the demand side, the choice between a new system or the prematurely decommissioned PV system with a certain capacity (in kWp) will strongly depend on the LCOE of both scenarios. Specifically, the LCOE of the prematurely decommissioned panels must be lower than, or at least the same as, the LCOE of a system with new panels. The maximum price of the prematurely decommissioned panels is reached at LCOE parity:

$$
L C O E^{u}=L C O E^{n}
$$

Where

$$
\begin{array}{ll}
u \quad \begin{array}{l}
\text { Scenario with prematurely } \\
\text { decommissioned panels }
\end{array} \\
n \\
\text { Scenario with new panels }
\end{array}
$$

Annual OPEX is assumed to be the same for both systems, regardless of whether the panels are new or decommissioned. The same is true for the yield.

The BOS can be further divided into area-dependent and area-independent components. Area-dependent components include cables and mounting structure. Area-independent components include the inverter. Because the total capacity of both installations is the same, CAPEX for the area-independent components (inverter) is assumed to be equal for both scenarios. CAPEX for the area-dependent components, however, is higher for the prematurely decommissioned PV panels, because they tend to have lower power density than new ones. This means a larger surface area is required to reach the same system capacity. 
Two key variables are the remaining power and the remaining lifetime of the prematurely decommissioned panel. This remaining power is benchmarked to the power of a marketaverage new panel manufactured in 2020 :

$$
P^{u}=a \times P^{n}
$$

Where
$P$
Total power of the system [kWp]
a
Remaining power share of prematurely decommissioned panels, compared to new panels

For example, new PV panel power in 2020 is assumed to be around $310 \mathrm{Wp}$ (24), while a prematurely decommissioned panel manufactured in 2010 had a peak power of about $240 \mathrm{Wp}$ when it was brought to market (22). With normal field degradation rates, the power of the prematurely decommissioned PV panel would have decreased to about $224 \mathrm{Wp}$ in 2020. The remaining power share is therefore $72 \%(224 \mathrm{Wp} / 310 \mathrm{Wp})$.

CAPEX for the area-dependent components for prematurely decommissioned panels will then be (assuming the area is equal in both scenarios):

$$
\text { Price }_{B O S_{\text {Area }}}^{u}=\frac{1}{a} \times \text { Price }_{B O S_{\text {Area }}}^{n}
$$

Where

BOS_Area

Area-dependent BOS

Taking into account the above as well as the equal yield for both installations, Equation (7) can be rewritten as:

$$
\begin{aligned}
& \text { Price }_{P V}^{u}+\text { Price }_{B O S_{\text {NonArea }}}+\left(\frac{1}{a} \times \text { Price }_{B O S_{\text {Area }}}^{n}\right)+\text { OPEX }_{t=1}^{N} \frac{1}{1+W A C C_{n o m}}{ }^{t} \\
& \sum_{t=1}^{N} \frac{(1-\text { Degradation })^{t}}{\left(1+W A C C_{\text {real }}\right)^{t}} \\
& =\frac{\text { Price }_{P V}^{n}+\text { Price }_{\text {BOS }_{\text {NonArea }}}+\text { Price }_{B O S_{\text {Area }}}^{n}+\text { OPEX } \sum_{t=1}^{N} \frac{1}{1+W A C C_{\text {nom }}}}{\sum_{t=1}^{N} \frac{\left(1-\text { Degradation }^{t}\right.}{\left(1+\text { WACC }_{\text {real }}\right)^{t}}}
\end{aligned}
$$

Where

$$
\text { BOS_NonArea Area-independent BOS }
$$

A convenient equation to calculate the sum of power series is:

$$
\sum_{t=1}^{N} X^{t}=\frac{X^{N+1}-1}{X-1}-1
$$

By substituting the summations in the numerator and denominator of Equation (10) with this power series, the maximum price for prematurely decommissioned panels can be calculated analytically. Input parameters for the calculation are listed in Table 7. 
Table 7: Default parameter values for LCOE parity calculations

\begin{tabular}{|c|c|c|c|}
\hline Parameter & Unit & Value & Source \\
\hline $\begin{array}{l}\text { Price, new mainstream PV panel } \\
\left(\text { Price }_{P V}^{n}\right)\end{array}$ & $€ / k W p$ & 250 & (23) \\
\hline $\begin{array}{l}\text { Price, BOS area-dependent } \\
\text { components, when new panels are } \\
\left.\text { installed (Price } \text { BOS }_{\text {Area }}\right)\end{array}$ & $€ / k W p$ & 152 & Calculated from (22) \\
\hline $\begin{array}{l}\text { Price, BOS area-independent } \\
\left.\text { components (Price } \text { BOS }_{\text {NonArea }}\right)\end{array}$ & $€ / k W p$ & 41 & Calculated from (22) \\
\hline Annual OPEX (OPEX) & $€ / k W p$ & 17 & $\begin{array}{l}\text { CIRCUSOL } \\
\text { partner }\end{array}$ \\
\hline $\begin{array}{l}\text { Yearly field degradation rate } \\
\text { (Degradation) }\end{array}$ & $\%$ & 0,7 & (8) \\
\hline Lifetime of new panels $(N)$ & years & 30 & (8) \\
\hline WACC, nominal (WACC $\left.C_{\text {nom }}\right)$ & $\%$ & 7 & (24) \\
\hline WACC, real $\left(W^{\prime} A C C_{\text {real }}\right)$ & $\%$ & 4,90 & $\begin{array}{l}\text { Calculated } \\
\text { inflation of } 2 \%\end{array}$ \\
\hline
\end{tabular}

The WTP for panels with different remaining powers and lifetimes is plotted in Figure 8 (see detailed numbers in Annex B). The lines for panels with a greater remaining lifetime are above the lines for panels with a lower remaining lifetime. The upward slope of the lines indicates that the WTP increases as the remaining share of power increases. Therefore, the results in Figure 8 demonstrate that the WTP for prematurely decommissioned panels with a greater remaining power and lifetime is higher than for those with a lower remaining power and lifetime.

Reuse of prematurely decommissioned panels will potentially have a positive economic value only when the WTP is higher than zero. For the example of healthy 2010 panels with a remaining power share of $72 \%$ and 20 years of remaining lifetime, the WTP would be 108 $€ / k W p$. 


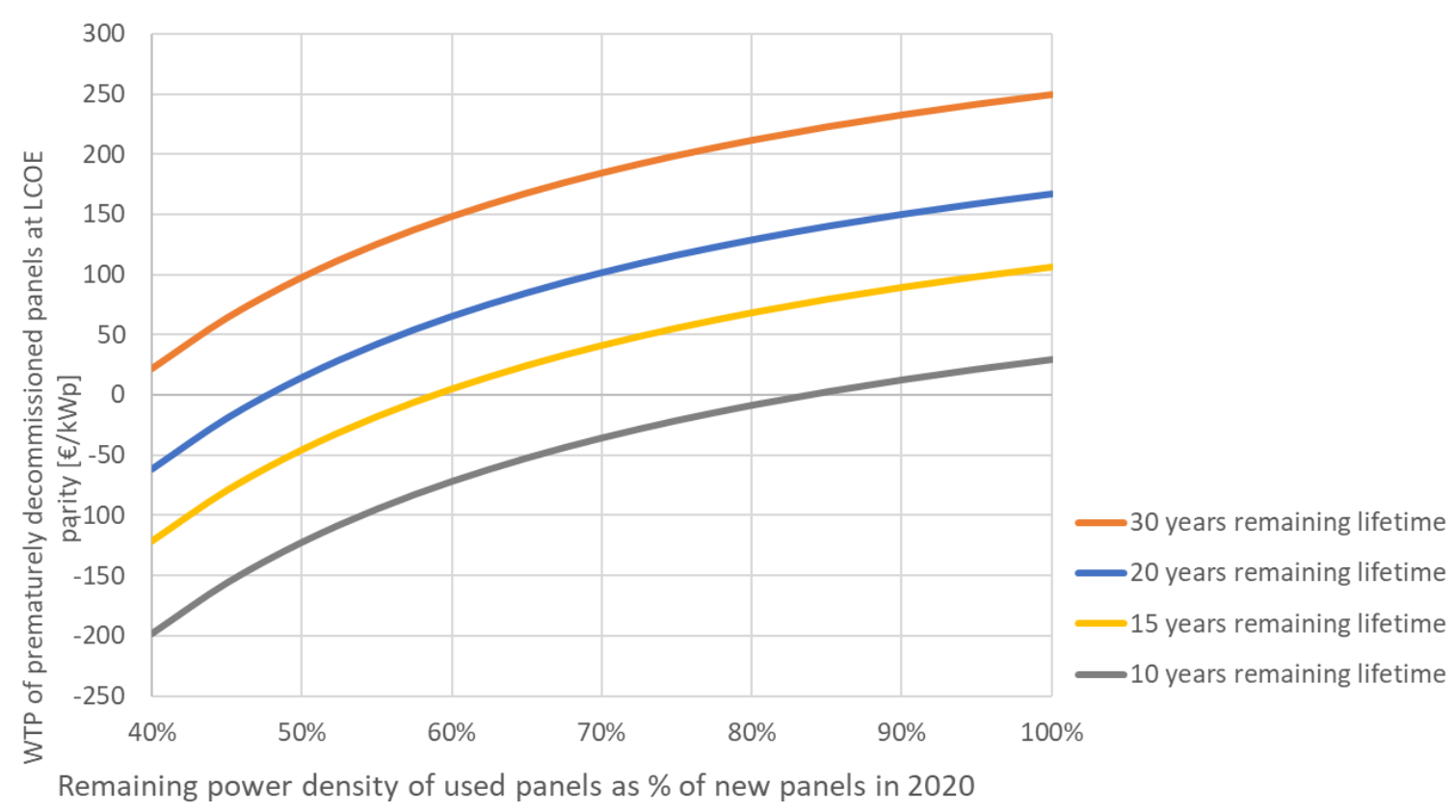

Figure 8: The evolution of WTP for prematurely decommissioned PV, at LCOE parity with new PV and in terms of its remaining power share and lifetime. At a remaining power share of $100 \%$ and with 30 years of lifetime remaining, the WTP for prematurely decommissioned PV is equal to the WTP for new PV.

\subsection{Supply Side: Willingness to Send Prematurely Decommissioned PV to Reuse or Recycle}

When repowering a utility-scale PV system, there are two EOL treatment options for the used panels: selling them, for reinstallation or recycling them. From this PV supply perspective, the potential cashflows to be considered in the EOL decision are listed in Table 8.

Table 8: Potential PV EOL cashflows

\begin{tabular}{|lll|}
\hline Revenue & $\begin{array}{l}\text { Sales price of prematurely decommissioned } \\
\text { panel }\end{array}$ & 0 \\
\hline Cost & Reuse costs & Recycling costs \\
\hline \hline Profit & Sales price - reuse costs & $\mathbf{0}$ - recycling costs \\
\hline
\end{tabular}

Financially speaking, the supply side will only opt for the reuse route if it brings higher profits, so if:

Sales price - reuse costs $>-$ recycling costs 
In other words, the additional costs to reuse rather than recycle must be lower than the potential sales price of the prematurely decommissioned panel:

\section{Reuse costs - recycling costs $<$ sales price}

Common costs applicable to reuse and recycling are the decommissioning costs. Decommissioning costs for reuse may be higher, because more careful handling may be required, although no clear indications are available for the decommissioning of the panels alone (while maintaining the BOS). For this preliminary analysis, we consider the decommissioning costs to be equal in both cases.

Costs specific to sending panels for recycling include gate fees charged by recycling facilities. Gate fees vary substantially from country to country, or even within countries (as in the United States). In Europe, they can be considered zero, because an extended producer responsibility system is in place for electronics; collection, sorting, and recycling of PV waste is prepaid by the panel manufacturer or-for PV produced outside of Europe-the entity bringing the panels into the European market. ${ }^{2}$ To be conservative about the business case for reuse, no costs related to sending panels for recycling are taken into account in this analysis.

Costs specific to reuse may include cleaning, handling, repairing, testing, and recertification. These costs will vary depending on local labour costs. Cost estimations for Germany and Belgium are shown in Table 9, based on averaged inputs from CIRCUSOL project partners and stakeholders representing costs experienced in the years 2018 and 2019 (personal communication). 
Table 9: PV reuse cost overview (all costs reported in $€$ )

\begin{tabular}{|c|c|c|c|}
\hline Average costs [€/panel] & Healthy panels & $\begin{array}{l}\text { Panels with diode } \\
\text { failure }\end{array}$ & $\begin{array}{l}\text { Panels with } \\
\text { junction box } \\
\text { failure }\end{array}$ \\
\hline Dismantling/decommissioning & \multicolumn{3}{|c|}{$\begin{array}{l}\text { Assumed same as recycling (although panels intended for reuse may } \\
\text { need more careful handling) }\end{array}$} \\
\hline Visual inspection \& handling & 18 & 18 & 18 \\
\hline Cleaning & 2 & 2 & 2 \\
\hline Repair & 0 & $5-10$ & 40 \\
\hline Testing & Not included & Not included & Not included \\
\hline Recertification & Not included & Not included & Not included \\
\hline Total [€/panel] & $\begin{array}{l}20+\text { testing \& } \\
\text { transport }\end{array}$ & $\begin{array}{l}25-30+\text { testing \& } \\
\text { transport }\end{array}$ & $\begin{array}{l}60+\text { testing \& } \\
\text { transport }\end{array}$ \\
\hline $\begin{array}{l}\text { Total }[€ / \mathrm{kWp}] \\
\text { if panel }=250 \mathrm{Wp}\end{array}$ & $\begin{array}{l}80 \text { + testing \& } \\
\text { transport }\end{array}$ & $\begin{array}{l}\text { 100-120 + testing \& } \\
\quad \text { transport }\end{array}$ & $\begin{array}{l}240+\text { testing \& } \\
\text { transport }\end{array}$ \\
\hline
\end{tabular}

Testing and recertification costs are not taken into account in the analysis, because they can vary significantly depending on the type of tests, level of automation, and labour costs. According to CIRCUSOL partners (personal communication), the costs for electroluminescence and IV-curve testing, for example, may range from $15 € /$ panel or less if testing takes place in a fully automated process, to $100 € /$ panel. On the other hand, for sufficiently large batches, other consortium partners indicate an average cost of $20 € /$ panel for the entire process of rehabilitation for reuse, including visual inspection, handling, testing, and minor repairs. Additional data collection and case studies are needed to develop a more robust understanding of the range of costs and factors that contribute to cost variation before drawing any general conclusions about costs for reuse. It also remains unclear which standards and/or certifications will be required for increasing reuse of prematurely decommissioned PV panels, for instance to allow for repaired PV panels to be deployed in grid-tied applications (as opposed to the off-grid market), but also to build general market confidence in prematurely decommissioned panels.

Although transportation distances may differ, both the reuse and recycling scenarios require transport of the panels. The transportation cost is estimated to be about $0,1 € /$ panel $/ 100 \mathrm{~km}$. Within Europe, it will probably not exceed $15 € / \mathrm{kWp}$ (at $3.000 \mathrm{~km}$ ). 


\subsection{Financial Viability Zone of PV Reuse}

In Figure 9, the additional costs related to reuse of prematurely decommissioned PV panels (including cleaning, handling, and repairing but not testing, recertification, and transportation) are added to the WTP graphs from Figure 8. The areas where the WTP curves (determined from LCOE parity calculations between new and prematurely decommissioned PV) surpass the minimum cost lines (green dashed lines) is where reuse of prematurely decommissioned panels could be financially viable from the supply and demand perspectives-because the WTP for prematurely decommissioned panels on the demand side offsets the costs borne by the supply side.

Taking into account a remaining power density of $72 \%$ as calculated in Section 2.2, reuse is financially viable for healthy panels up to 10-12 years old (remaining lifetime around 20 years, given the lifetime of 30 years). The same is true for panels with an early failure in diode or cables, up to 5-10 years old (remaining lifetime of 20-25 years). In general, there is a business case for reuse of relatively young panels with a high remaining power share. Not surprisingly, reuse cannot compete with recycling for panels with a junction box failure, because repairing this failure is simply too costly.

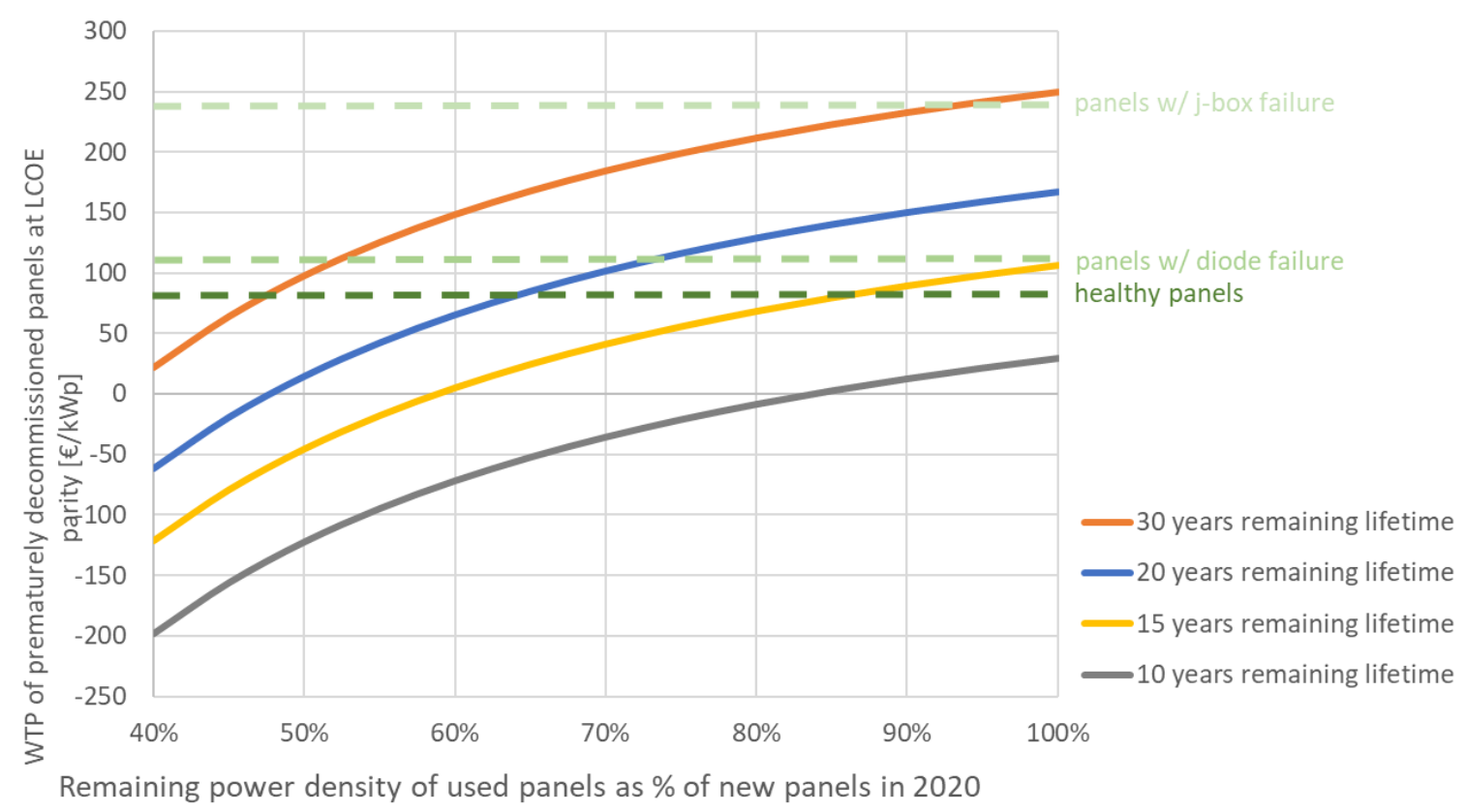

Figure 9: Financially viable zones for reuse of prematurely decommissioned PV panels. The solid coloured lines express the WTP for prematurely decommissioned panels on the buyer side, in terms of the remaining power share and remaining lifetime of the panels. To make PV reuse financially viable, this WTP should be higher than the costs incurred by the supplier of the prematurely decommissioned panels, shown as green dashed lines. These costs are heavily influenced by the state of the panels and the repair activities required. 


\section{REUSE OF PREMATURELY DECOMMISSIONED PV PANELS IN PRACTICE}

For the generic case described above, the LCOE metric is used as a starting point to evaluate the financial viability of reusing prematurely decommissioned PV panels. However, choosing the KPI most suitable for comparing different energy solutions is very context and case dependent. Therefore, we introduce here two example "real life" case studies. One takes the perspective of households investing in rooftop PV panels for self-consumption; because only costs are taken into account, LCOE is a useful metric to compare prematurely decommissioned PV with new PV. For the investment market operating at commercial or utility scale, however, profitability of the investment is crucial. Because LCOE does not account for financial returns, other financial KPIs—such as net present value (NPV)—are more suitable. Both perspectives are discussed in the following sections.

\subsection{LCOE for Residential Self-Consumption}

Households installing rooftop PV mostly aim to profit from the electricity via self-consumption. This is the case for the example discussed here, a co-housing community in Belgium.

The community must consider the financial implications of investing in new PV panels or prematurely decommissioned PV panels (from 2010, with 20 years of remaining technical lifetime). A good approach is to base the investment decision on an LCOE comparison of both scenarios, taking into account site-specific parameters. The roof surface of the co-housing site offers space for 321 panels at maximum, and-owing to the location and orientation of the installation-its yield is limited to $575 \mathrm{kWh} / \mathrm{kWp}$. Reverse (aka "net") metering is in place, and the tariff charged for electricity consumed from the grid is $0,16 € / \mathrm{kWh}$. From the perspective of the co-housing community, this tariff can be considered the LCOE for electricity from the grid, representing the Belgian electricity mix in 2020. The community consists of 22 households, and the yearly electricity requirement is $83.557 \mathrm{kWh}$. A time horizon of 30 years, corresponding to the technical lifetime of PV panels, is considered to allow for accurate comparison of the scenarios.

The parameters in 
Table 10 are taken into account when comparing the new panels and the prematurely decommissioned PV panels. The price of prematurely decommissioned PV panels is assumed to be $100 € / \mathrm{kWh}$, slightly below the maximum WTP of $108 € / \mathrm{kWh}$ as determined in Section 2.2. The inverter is expected to need replacement after 15 years. This is taken into account in the price for area-independent BOS. The nominal WACC is $7 \%$, and inflation and grid tariff indexation are assumed to be $2 \%$, resulting in a real WACC of $4,90 \%$. 
Table 10: Scenario specifications for new and prematurely decommissioned PV panels (prices exclude value-added tax [VAT])

\begin{tabular}{|lll|}
\hline & New panels from 2020 & $\begin{array}{l}\text { Prematurely } \\
\text { decommissioned PV } \\
\text { panels (manufactured in } \\
2010)\end{array}$ \\
\hline Panel peak power [Wp] & & 224 \\
\hline Remaining PV lifetime [years] & 310 & 20 \\
\hline Price of panels [€/kWp] & 30 & 100 \\
\hline Price of area-dependent BOS [€/kWp] & 152 & 210 \\
\hline $\begin{array}{l}\text { Price of area-independent BOS } \\
{[€ / k W p]}\end{array}$ & 75 & 75 \\
\hline Annual OPEX [€/kWp] & 17 & 17 \\
\hline Yearly degradation rate [\%] & 0,7 & 0,7 \\
\hline
\end{tabular}

The overall CAPEX (sum of prices of panels, area-dependent BOS, and area-independent BOS in 
Table 10) for prematurely decommissioned PV panels is lower than for new PV. However, when comparing the LCOE of both scenarios-applying Equation (10) and taking into account a VAT tariff of $21 \%$ on all expenses - the LCOE for prematurely decommissioned PV panels is higher than for new panels (Table 11). This is mainly due to the limited remaining technical lifetime of prematurely decommissioned PV panels. From the perspective of the co-housing community, it is therefore financially more beneficial to install new PV panels.

The result is further reinforced by the lower power density of prematurely decommissioned PV panels in combination with the surface restriction of 321 panels. This means a smaller share of the community's yearly electricity requirement can be covered by prematurely decommissioned panels than by new panels. In the year of installation, the rate of selfsufficiency is only $49,50 \%(41.344,80 \mathrm{kWh} / 83.557 \mathrm{kWh})$ with prematurely decommissioned panels, but $68,50 \%(57.218,25 \mathrm{kWh} / 83.557 \mathrm{kWh})$ with new PV. These rates decrease over time as efficiency degrades. The remaining share of electricity required is covered by the grid at a cost of $0,16 € / \mathrm{kWh}$. During the final 10 years of the 30 -year horizon, the co-housing community solely relies on grid electricity in the scenario with reuse of prematurely decommissioned panels, because the remaining panel lifetime is only 20 years and we assume they are not replaced. For each year in the time horizon, the actual LCOE is calculated as the weighted average of the grid LCOE and PV LCOE. Not only does the self-sufficiency rate change on a yearly basis due to PV efficiency degradation, but also the grid LCOE (grid prices) are subject to a yearly indexation of $2 \%$ :

$$
L C O E_{\text {weighted }}^{t}=s^{t} \times L C O E_{P V}+\left(1-s^{t}\right) \times L C O E_{\text {grid }}^{t}
$$

Where

$$
\begin{aligned}
& s^{t} \\
& L_{C O E} E_{P V} \\
& L C O E_{\text {grid }}^{t}
\end{aligned}
$$

Rate of self-sufficiency in year $t$ [\%]

PV system LCOE $[€ / \mathrm{kWh}]$

LCOE for electricity from the grid in year $t$ $[€ / \mathrm{kWh}]$

An overview of the self-sufficiency and weighted LCOE evolution for both scenarios is provided in Annex B.

Over the entire 30-year horizon (N), the overall LCOE can be calculated as follows:

$$
L C O E_{\text {overall }}=\sum_{t=1}^{N} \frac{L C O E_{\text {weighted }}^{t}}{N}
$$

The overall LCOE numbers are summarized in Table 11. They are of course heavily influenced by the grid tariff, which is country and case specific.

Table 11: LCOE scenario results for new and prematurely decommissioned PV panels

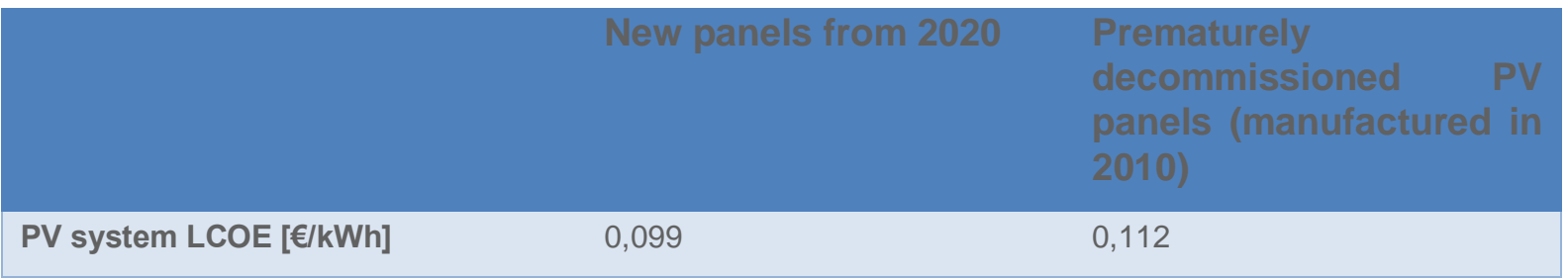


PV electricity production in year of $57.218,25$ installation [kWh]

Rate of self-sufficiency in the year of 68,50

installation [\%]

Overall LCOE [€/kWh]
0,146

0,193
$41.344,80$

49,50

In conclusion, the limited remaining technical lifetime of prematurely decommissioned PV panels negatively impacts the use case, while surface-area restrictions-which are often in place in residential settings-further decrease the potential for the reuse of prematurely decommissioned panels to be financially competitive with new PV owing to the lower power densities of the prematurely decommissioned panels.

\subsection{Beyond LCOE for the Utility Market}

Beyond LCOE, there are other important decision factors for PV reuse, especially within the investment market for commercial- or utility-scale PV installations. Whereas LCOE focuses on the cost perspective, investment cases are often evaluated based on other financial KPIs, such as NPV. NPV represents the difference between the present value of revenues and costs for a given period. It is used to analyse the profitability of a projected investment or project over its entire lifetime. The higher the NPV of an investment, the better. The following example illustrates the use of NPV.

For the demand-side case of a European utility-scale PV plant of $10 \mathrm{MWp}$, an investment decision must be made between new and prematurely decommissioned PV panels. The scenario parameters taken into account are listed in Table 12. An average yield of 1.090 $\mathrm{kWh} / \mathrm{kWp}$ is assumed, and inverters are assumed to need replacement after 15 years (accounted for in the price of area-independent BOS). Again, the nominal WACC is 7\% and inflation is $2 \%$, resulting in a real WACC of $4,90 \%$. Revenue of $0,05 € / \mathrm{kWh}$ for electricity sold to the grid is assumed, although this number can fluctuate considerably in reality.

Table 12: Scenario specifications for new and prematurely decommissioned PV panels (prices exclude VAT)

\begin{tabular}{|c|c|c|}
\hline & $\begin{array}{l}\text { New PV } \\
\text { panels from } \\
2020\end{array}$ & $\begin{array}{l}\text { Prematurely decommissioned PV panels } \\
\text { (manufactured in 2010) }\end{array}$ \\
\hline Panel peak power [Wp] & 310 & 224 \\
\hline Remaining PV lifetime [years] & 30 & 20 \\
\hline Price of panels [€/kWp] & 250 & 100 \\
\hline $\begin{array}{l}\text { Price of area-dependent BOS } \\
{[€ / \mathrm{kWp}]}\end{array}$ & 152 & 210 \\
\hline $\begin{array}{l}\text { Price of area-independent BOS } \\
{[€ / \mathrm{kWp}]}\end{array}$ & 75 & 75 \\
\hline Annual OPEX [€/kWp] & 17 & 17 \\
\hline Yearly degradation rate [\%] & 0,7 & 0,7 \\
\hline
\end{tabular}


The NPV for both investment options can be calculated as follows:

$$
N P V=\sum_{t=1}^{N} \frac{C F^{t}}{\left(1+W A C C_{\text {real }}\right)^{t}}=\sum_{t=1}^{N} \frac{R^{t}-\left(C A P E X^{t}+O P E X^{t}\right)}{\left(1+W A C C_{\text {real }}\right)^{t}}
$$

Where

$$
\begin{array}{ll}
C F^{t} & \text { Net cashflow (revenues - costs) in year } t[€] \\
R^{t} & \text { Total revenues in year } t[€]
\end{array}
$$

This can be rewritten as follows:

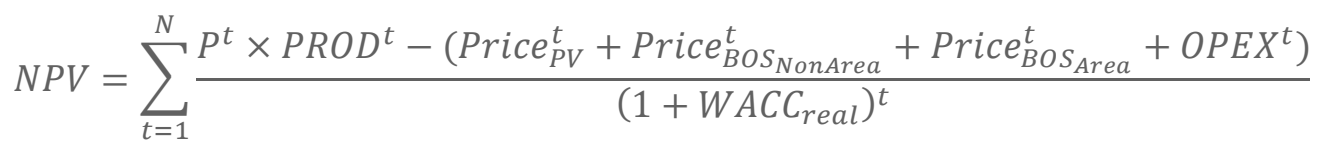

Where

$$
\begin{array}{ll}
P^{t} & \text { Revenue for a kWh electricity sold to the grid in year } t[€ / \mathrm{kWh}] \\
P R O D^{t} & \text { PV electricity production in year } t[\mathrm{kWh}]
\end{array}
$$

To allow for accurate comparison of both scenarios without predicting future prices and PV efficiency evolutions (potentially making the calculations less robust), the time horizon is normalized to 20 years. CAPEX parameters are taken into account proportionally whenever required. ${ }^{3}$ As shown in Table 13, the NPV for the scenario with reuse of prematurely decommissioned panels is lower than for the one with new panels. Although the investment cost for reusing prematurely decommissioned panels is lower than for using new panels, the result is heavily influenced by the shorter technical lifetime of 20 years (rather than 30 years for new panels), as in the residential case.

Table 13 shows that more panels, and thus a larger surface area, are required in the prematurely decommissioned panels scenario to reach the system capacity of $10 \mathrm{MWp}$, owing to the lower power density of the prematurely decommissioned panels. In this sense, the analysis above assumes an unlimited amount of land is available. However, commercial- and utility-scale settings often entail surface-area restrictions, favouring the scenario with new panels even more. New panels generate more power per unit of area, so more efficient use can be made of the available space. If no more than 32.258 panels could be installed (the number of panels in the scenario with new PV), reusing prematurely decommissioned panels becomes even less financially competitive than using new panels, as shown in Table 13.

Table 13: NPV scenario results for new and prematurely decommissioned PV panels

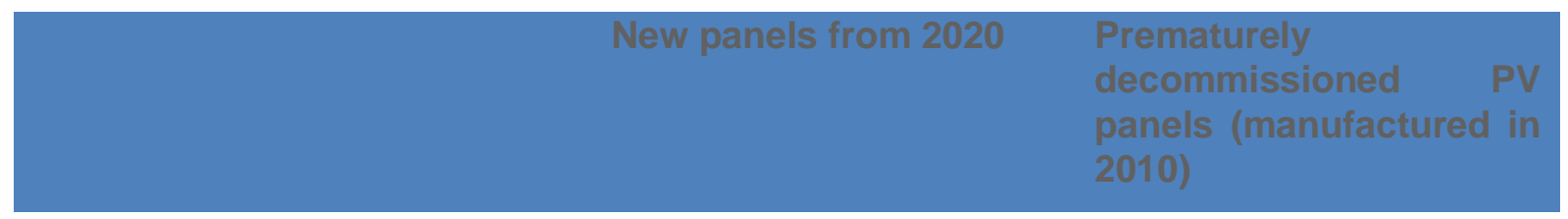

\footnotetext{
${ }^{3}$ For example, new PV has an expected technical lifetime of 30 years. Because only the first 20 years are included in the analy sis, only two thirds of the PV CAPEX is taken into account in the calculations.
} 


\begin{tabular}{|l|l|l|}
\hline Number of panels installed & 32.258 & 44.643 \\
\hline $\begin{array}{l}\text { PV electricity production in year of } \\
\text { installation [kWh] }\end{array}$ & $10.900 .000,00$ & $10.900 .000,00$ \\
\hline NPV [€] & 1.423 .714 & 1.182 .470 \\
\hline Situation with limited surface availability & \\
\hline Number of panels installed & 32.258 & 32.258 \\
\hline $\begin{array}{l}\text { PV electricity production in year of } \\
\text { installation [kWh] }\end{array}$ & $10.900 .000,00$ & $7.876 .129,03$ \\
\hline NPV with surface restrictions [€] & 1.423 .714 & 577.554 \\
\hline
\end{tabular}




\section{DISCUSSION AND CONCLUSION}

As discussed in Part B, reusing PV panels proves financially competitive with a business-asusual scenario that combines new PV on the demand side with PV recycling on the supply side. When taking the LCOE perspective, under certain conditions the WTP for prematurely decommissioned PV surpasses the cost incurred for supplying those panels. Our analysis suggests this is the case for relatively young panels (up to around 10 years old) with few or no defects (healthy panels or diode/cable failures only). We do not account for testing and recertification costs, because those costs are heavily influenced by labour costs and thus are very context and region specific. However, depending on the volumes treated, these costs could be a determining factor for the success of the reuse business case. Additional empirical data on the required rehabilitation processes (including handling, cleaning, and potential repair) must be developed to optimize the trade-off of testing and recertification costs versus confidence in remaining power and lifetime. Transportation costs are unlikely to have a significant impact on the financial viability of PV reuse, especially if reuse takes place within Europe; our analysis shows a cost of only $0,1 € /$ panel $/ 100 \mathrm{~km}$.

However, LCOE is not the only decision factor related to reusing prematurely decommissioned PV. From the demand side of the residential market where PV is meant for self-consumption and costs are the main decision driver, reusing prematurely decommissioned PV does not appear to be financially desirable owing to surface-area restrictions as well as the lower remaining power density and limited remaining lifetimes of prematurely decommissioned panels. In addition, our analysis of PV as a utility-scale investment-using NPV as the KPIsuggests that new panels are more attractive than prematurely decommissioned panels in this context as well, with and especially without surface-area limits. In reality, the financial viability of the reuse business case is influenced by additional country- and case-specific parameters, such as the grid tariffs that drive revenue and can fluctuate substantially. These revenuestogether with PV efficiency improvements, price changes, and area restrictions-drive investment decisions.

This report provides an exploratory analysis of the business case for reusing prematurely decommissioned PV; additional research is required before drawing definite conclusions. Continuing improvements in PV efficiency and price reductions further reinforce the business case for new PV. Efficiency improvements and price decreases are expected to continue, although likely at a slower rate than in the past. If efficiencies and prices eventually stabilize, reusing prematurely decommissioned PV might become increasingly competitive with using new PV. However, reuse requires efficient rehabilitation and repair processes, recertification procedures for prematurely decommissioned PV, and transparent communication about the remaining lifetime and peak power of prematurely decommissioned panels. Other aspectsincluding aesthetics, policies, user profiles, and technical aspects-could lead to additional business opportunities for PV reuse outside of the discussed markets, especially if potential electricity generation from available rooftop or land area is higher than electricity consumption. 


\section{Annex Part A}

\section{ANNEX A - 1: LCIA FOR THE PV SYSTEM: MAIN ENVIRONMENTAL IMPACT CATEGORY RESULTS FOR SEPARATE COMPONENTS AND LIFE CYCLE STAGES (MANUFACTURING AND RECYCLING)}

Life cycle (manufacturing and recycling) environmental impacts of panel, inverter, mounting system, and other parts of the BOS. The first row (in bold) represents the total single score of each component, while the remaining rows represent midpoint environmental impacts. Recycling has been modelled using the recycled content approach.

\begin{tabular}{|c|c|c|c|c|c|c|}
\hline Impact per panel & Unit & $\begin{array}{l}\text { Manufact } \\
\text { uring PV } \\
\text { - } 1 \text { panel }\end{array}$ & $\begin{array}{c}\text { Recyc } \\
\text { ling } \\
\text { PV - } 1 \\
\text { panel }\end{array}$ & $\begin{array}{l}\text { Inver } \\
\text { ter - } \\
\text { per } \\
\text { pane } \\
\text { I }\end{array}$ & $\begin{array}{c}\text { PV } \\
\text { moun } \\
\text { ting } \\
\text { syste } \\
\text { m - } \\
\text { per } \\
\text { panel }\end{array}$ & $\begin{array}{c}\text { BOS } \\
\text { (excl. } \\
\text { invert } \\
\text { er } \\
\text { and } \\
\text { moun } \\
\text { ting } \\
\text { syste } \\
\text { m) - } \\
\text { per } \\
\text { panel }\end{array}$ \\
\hline Single score & $\mathrm{mPts}$ & $6,11 \mathrm{E}+01$ & 2,95E-01 & $\begin{array}{c}2,83 \mathrm{E}+ \\
01\end{array}$ & $\begin{array}{c}5,83 \mathrm{E}+0 \\
0\end{array}$ & $\begin{array}{c}1,05 \mathrm{E}+0 \\
1\end{array}$ \\
\hline Climate change & $\mathrm{kg} \mathrm{CO}$ eq & $4,31 E+02$ & $\begin{array}{c}3,59 \mathrm{E}+0 \\
0\end{array}$ & $\begin{array}{c}4,29 \mathrm{E}+ \\
01\end{array}$ & $\begin{array}{c}6,90 \mathrm{E}+0 \\
1\end{array}$ & $\begin{array}{c}1,32 \mathrm{E}+0 \\
1\end{array}$ \\
\hline Ozone depletion & $\mathrm{kg} \mathrm{CFC11} \mathrm{eq}$ & 2,82E-05 & $5,52 \mathrm{E}-07$ & $\begin{array}{l}3,59 \mathrm{E}- \\
06\end{array}$ & $\begin{array}{c}2,53 \mathrm{E}- \\
06\end{array}$ & $\begin{array}{c}7,27 \mathrm{E}- \\
07\end{array}$ \\
\hline lonizing radiation, human health & kBq U-235 eq & $1,64 \mathrm{E}+01$ & $2,05 \mathrm{E}-01$ & $\begin{array}{c}2,11 \mathrm{E}+ \\
00\end{array}$ & $\begin{array}{c}1,09 \mathrm{E}+0 \\
0\end{array}$ & $\begin{array}{c}2,93 \mathrm{E}- \\
01\end{array}$ \\
\hline $\begin{array}{l}\text { Photochemical ozone formation, } \\
\text { human health }\end{array}$ & $\mathrm{kg} N M V O C$ eq & $2,55 \mathrm{E}+00$ & $5,82 \mathrm{E}-03$ & $\begin{array}{c}1,93 \mathrm{E}- \\
01\end{array}$ & $\begin{array}{c}2,08 \mathrm{E}- \\
01\end{array}$ & $\begin{array}{c}1,38 \mathrm{E}- \\
01\end{array}$ \\
\hline Respiratory inorganics & disease inc. & 2,62E-05 & $6,90 \mathrm{E}-08$ & $\begin{array}{l}2,27 \mathrm{E}- \\
06\end{array}$ & $\begin{array}{c}4,48 \mathrm{E}- \\
06\end{array}$ & $\begin{array}{c}1,57 \mathrm{E}- \\
06\end{array}$ \\
\hline Non-cancer human health effects & CTUh & 1,27E-05 & $2,15 E-08$ & $\begin{array}{c}2,65 E- \\
06\end{array}$ & $\begin{array}{c}1,57 \mathrm{E}- \\
06\end{array}$ & $\begin{array}{c}7,62 \mathrm{E}- \\
06\end{array}$ \\
\hline Cancer human health effects & CTUh & 2,53E-07 & $9,25 \mathrm{E}-10$ & $\begin{array}{c}4,56 \mathrm{E}- \\
08\end{array}$ & $\begin{array}{c}8,64 \mathrm{E}- \\
08\end{array}$ & $\begin{array}{c}9,09 \mathrm{E}- \\
08\end{array}$ \\
\hline $\begin{array}{l}\text { Acidification terrestrial and } \\
\text { freshwater }\end{array}$ & $\mathrm{mol} \mathrm{H}^{+}$eq & $3,57 \mathrm{E}+00$ & $7,84 \mathrm{E}-03$ & $\begin{array}{c}3,76 \mathrm{E}- \\
01\end{array}$ & $\begin{array}{c}3,98 \mathrm{E}- \\
01\end{array}$ & $\begin{array}{c}6,76 \mathrm{E}- \\
01\end{array}$ \\
\hline Eutrophication freshwater & $\mathrm{kg} \mathrm{P}$ eq & 2,01E-02 & 4,52E-05 & $\begin{array}{c}8,29 \mathrm{E}- \\
03\end{array}$ & $\begin{array}{c}2,15 \mathrm{E}- \\
03\end{array}$ & $\begin{array}{c}\text { 5,35E- } \\
03\end{array}$ \\
\hline
\end{tabular}




\begin{tabular}{|c|c|c|c|c|c|c|}
\hline Impact per panel & Unit & $\begin{array}{l}\text { Manufact } \\
\text { uring PV } \\
\text { - } 1 \text { panel }\end{array}$ & $\begin{array}{c}\text { Recyc } \\
\text { ling } \\
\text { PV - } 1 \\
\text { panel }\end{array}$ & $\begin{array}{c}\text { Inver } \\
\text { ter - } \\
\text { per } \\
\text { pane } \\
\text { I }\end{array}$ & $\begin{array}{c}\text { PV } \\
\text { moun } \\
\text { ting } \\
\text { syste } \\
\text { m - } \\
\text { per } \\
\text { panel }\end{array}$ & $\begin{array}{c}\text { BOS } \\
\text { (excl. } \\
\text { invert } \\
\text { er } \\
\text { and } \\
\text { moun } \\
\text { ting } \\
\text { syste } \\
\text { m) - } \\
\text { per } \\
\text { panel }\end{array}$ \\
\hline Eutrophication marine & $\mathrm{kg} \mathrm{N} \mathrm{eq}$ & 7,93E-01 & $1,68 \mathrm{E}-03$ & $\begin{array}{c}5,58 \mathrm{E}- \\
02\end{array}$ & $\begin{array}{c}6,09 \mathrm{E}- \\
02\end{array}$ & $\begin{array}{c}\text { 3,38E- } \\
02\end{array}$ \\
\hline Eutrophication terrestrial & $\mathrm{mol} \mathrm{N}$ eq & $8,63 \mathrm{E}+00$ & 1,86E-02 & $\begin{array}{c}\text { 6,62E- } \\
01\end{array}$ & $\begin{array}{c}6,80 \mathrm{E}- \\
01\end{array}$ & $\begin{array}{c}\text { 4,99E- } \\
01\end{array}$ \\
\hline Ecotoxicity freshwater & CTUe & $1,36 \mathrm{E}+04$ & $\begin{array}{c}3,04 \mathrm{E}+0 \\
1\end{array}$ & $\begin{array}{c}4,39 \mathrm{E}+ \\
03\end{array}$ & $\begin{array}{c}1,59 E+0 \\
3\end{array}$ & $\begin{array}{c}6,53 \mathrm{E}+0 \\
3\end{array}$ \\
\hline Land use & $\begin{array}{l}\text { Soil quality } \\
\text { index (Pt) }\end{array}$ & $2,11 E+03$ & $\begin{array}{c}1,13 \mathrm{E}+0 \\
1\end{array}$ & $\begin{array}{c}2,19 \mathrm{E}+ \\
02\end{array}$ & $\begin{array}{c}1,32 \mathrm{E}+0 \\
2\end{array}$ & $\begin{array}{c}9,73 \mathrm{E}+0 \\
1\end{array}$ \\
\hline Water scarcity & $\mathrm{m}^{3}$ depriv. & $1,48 \mathrm{E}+02$ & $\begin{array}{c}8,08 \mathrm{E}+0 \\
0\end{array}$ & $\begin{array}{c}1,09 \mathrm{E}+ \\
01\end{array}$ & $\begin{array}{c}1,21 \mathrm{E}+0 \\
1\end{array}$ & $\begin{array}{c}6,87 \mathrm{E}+0 \\
0\end{array}$ \\
\hline Resource use, energy carriers & MJ & $4,99 \mathrm{E}+03$ & $\begin{array}{c}4,00 \mathrm{E}+0 \\
1\end{array}$ & $\begin{array}{c}5,39 \mathrm{E}+ \\
02\end{array}$ & $\begin{array}{c}7,74 \mathrm{E}+0 \\
2\end{array}$ & $\begin{array}{c}1,67 \mathrm{E}+0 \\
2\end{array}$ \\
\hline Resource use, minerals and metals & $\mathrm{kg} \mathrm{Sb}$ eq & $1,70 \mathrm{E}-02$ & $3,08 \mathrm{E}-05$ & $\begin{array}{c}\text { 1,92E- } \\
02\end{array}$ & $\begin{array}{c}2,84 \mathrm{E}- \\
04\end{array}$ & $\begin{array}{c}4,07 E- \\
03\end{array}$ \\
\hline
\end{tabular}




\section{ANNEX A - 2: LCIA FOR THE PV SYSTEM: MAIN ENVIRONMENTAL IMPACT CATEGORY RESULTS FOR TRANSPORT AND JUNCTION BOX REPLACEMENT}

Environmental impact (per panel) of junction box repair activities, including $1 \mathrm{~km}$ transportation by van. Single score impacts are given in the first row (in bold); the other rows contain values for the midpoint environmental impact categories. Transport is a single movement over $1 \mathrm{~km}$ with a van. Junction box repair is a single replacement.

\begin{tabular}{|c|c|c|c|}
\hline & Unit & $\begin{array}{l}\text { Transport of } 1 \text { panel with } \\
\text { commercial van over } 1 \\
\text { km }\end{array}$ & $\begin{array}{l}\text { Junction box } \\
\text { - per panel }\end{array}$ \\
\hline Single score & mPts & 2.95E-03 & $1.64 \mathrm{E}+00$ \\
\hline Climate change & $\mathrm{kg} \mathrm{CO} 2 \mathrm{eq}$ & 2.45E-02 & $6.63 \mathrm{E}+00$ \\
\hline Ozone depletion & $\mathrm{kg} \mathrm{CFC11} \mathrm{eq}$ & 5.10E-09 & 1.92E-07 \\
\hline lonizing radiation, human health & kBq U-235 eq & 1.66E-03 & 1.45E-01 \\
\hline $\begin{array}{l}\text { Photochemical ozone formation, } \\
\text { human health }\end{array}$ & kg NMVOC eq & 1.49E-04 & 3.03E-02 \\
\hline Respiratory inorganics & disease inc. & 2.43E-09 & 4.43E-07 \\
\hline Non-cancer human health effects & CTUh & $5.00 \mathrm{E}-10$ & 8.86E-07 \\
\hline Cancer human health effects & CTUh & 3.89E-11 & $1.13 \mathrm{E}-08$ \\
\hline Acidification terrestrial and freshwater & $\mathrm{mol} \mathrm{H}+\mathrm{eq}$ & 1.39E-04 & 1.02E-01 \\
\hline Eutrophication freshwater & $\mathrm{kg} P$ eq & 4.13E-07 & 8.59E-04 \\
\hline Eutrophication marine & $\mathrm{kg} \mathrm{N} \mathrm{eq}$ & 4.10E-05 & $1.11 \mathrm{E}-02$ \\
\hline Eutrophication terrestrial & $\mathrm{mol} \mathrm{N} \mathrm{eq}$ & 4.59E-04 & $1.06 \mathrm{E}-01$ \\
\hline Ecotoxicity freshwater & CTUe & 3.97E-01 & $8.55 \mathrm{E}+02$ \\
\hline Land use & $\mathrm{Pt}$ & $1.71 \mathrm{E}-01$ & $2.13 \mathrm{E}+01$ \\
\hline Water scarcity & $\mathrm{m}^{3}$ depriv. & $1.52 \mathrm{E}-03$ & $5.25 E+00$ \\
\hline Resource use, energy carriers & MJ & 3.63E-01 & $9.44 \mathrm{E}+01$ \\
\hline Resource use, minerals and metals & $\mathrm{kg} \mathrm{Sb}$ eq & 5.56E-07 & 4.78E-04 \\
\hline
\end{tabular}




\section{ANNEX A - 3: GLOBAL WARMING POTENTIAL FOR BASELINE SCENARIOS}

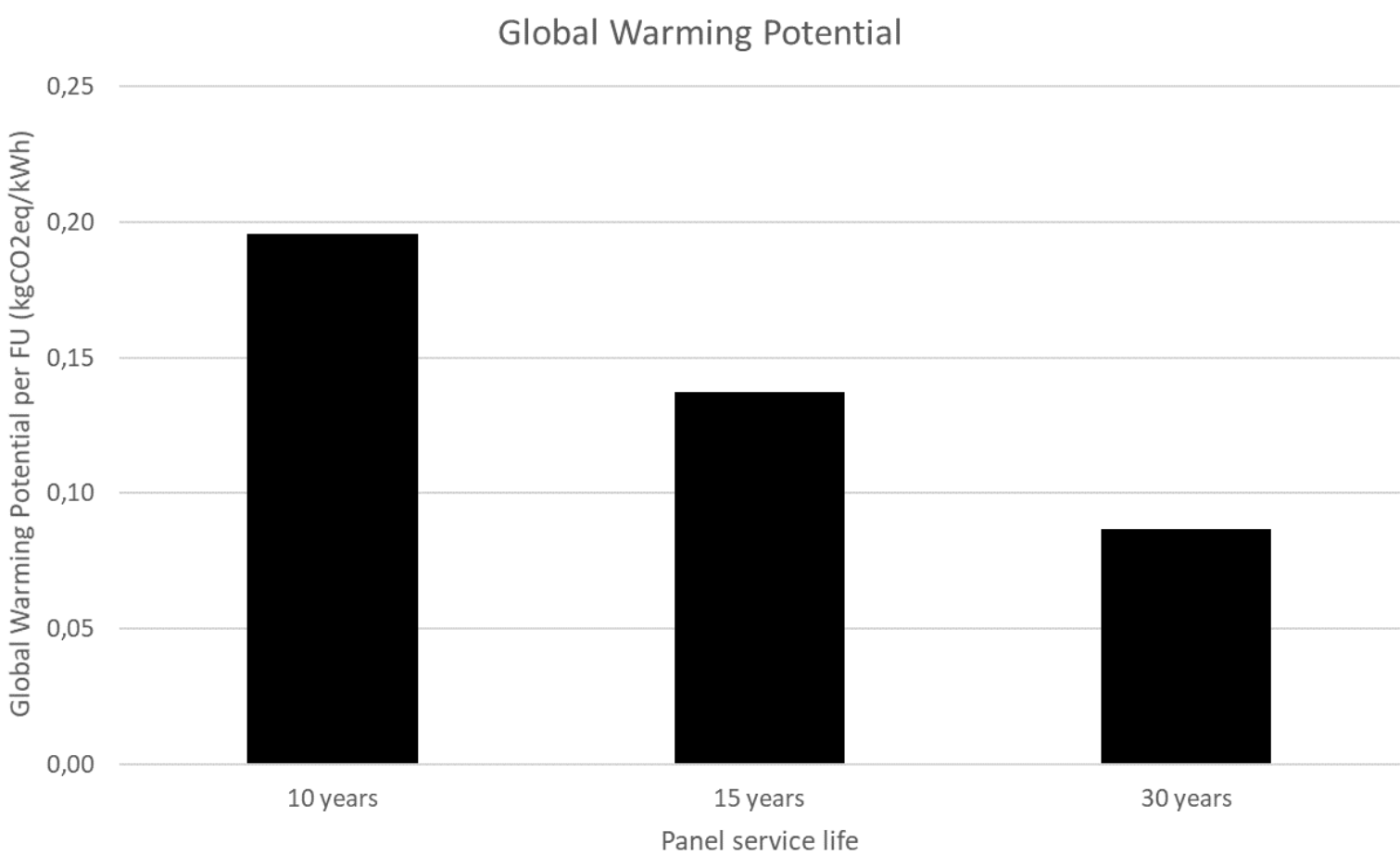

Environmental impact per functional unit (FU) with different panel service lifetimes, over a 30-year period. The figure represents the global warming impacts in $\mathrm{kg} \mathrm{CO}_{2} \mathrm{eq} / \mathrm{kWh}$. PV technology: multi-crystalline silicon. System type: rooftop (flat roof). Panel efficiency rate: variable, increases $1,4 \%$ every year. Panel efficiency in the first cycle: $14,7 \%$. Degradation rate: $0.7 \%$. PV lifetime: variable, 10,15 , or 30 years. BOS lifetime: variable, 10 or 15 years. Installation location: Europe. Annual irradiation: $1.331 \mathrm{kWh} / \mathrm{m}^{2}$ (average for Europe). Performance ratio: 82\% (excluding degradation). 


\section{ANNEX A - 4: RESOURCE USE, MINERALS AND METALS IMPACT FOR BASELINE SCENARIOS}

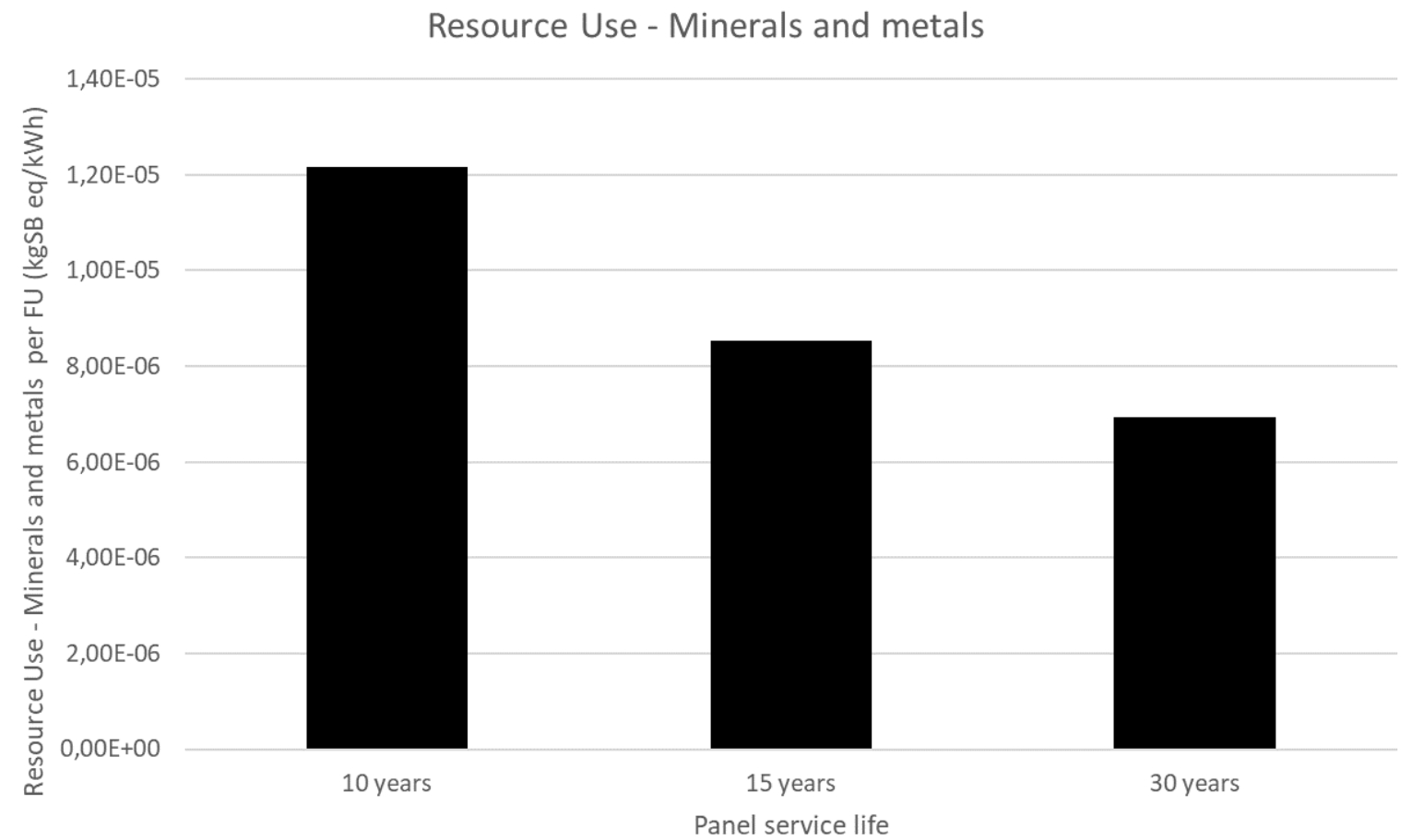

Environmental impact per FU with different panel service lifetimes, over a 30-year period. The figure represents the resource use, minerals and metals impacts in $\mathrm{kg}$ Sbeq/kWh. PV technology: multi-crystalline silicon. System type: rooftop (flat roof). Panel efficiency rate: variable, increases $1,4 \%$ every year. Panel efficiency in the first cycle: $14,7 \%$. Degradation rate: $0.7 \%$. PV lifetime: variable, 10,15 , or 30 years. BOS lifetime: variable, 10 or 15 years. Installation location: Europe. Annual irradiation: 1.331 $\mathrm{kWh} / \mathrm{m}^{2}$ (average for Europe). Performance ratio: 82\% (excluding degradation). 


\section{ANNEX A - 5: RESOURCE USE, ENERGY CARRIERS IMPACT FOR BASELINE SCENARIOS}

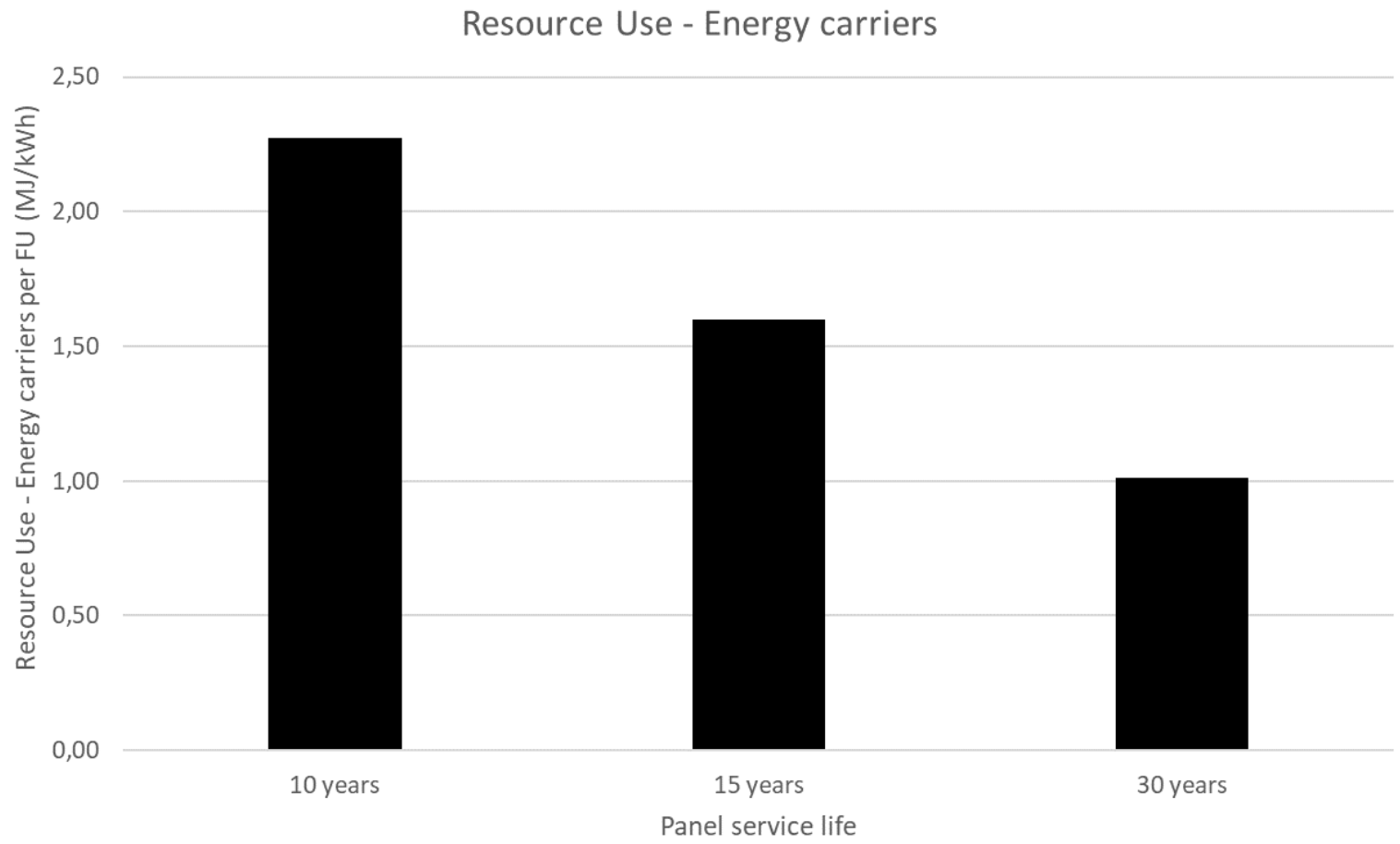

Environmental impact per FU with different panel service lifetimes, over a 30 -year period. The figure represents the resource use, energy carriers impacts in MJ/kWh. PV technology: multi-crystalline silicon. System type: rooftop (flat roof). Panel efficiency rate: variable, increases $1,4 \%$ every year. Panel efficiency in the first cycle: $14,7 \%$. Degradation rate: $\mathbf{0 . 7 \%}$. PV lifetime: variable, 10,15 , or 30 years. BOS lifetime: variable, 10 or 15 years. Installation location: Europe. Annual irradiation: $1.331 \mathrm{kWh} / \mathrm{m}^{2}$ (average for Europe). Performance ratio: 82\% (excluding degradation). 


\section{ANNEX A - 6: RESPIRATORY INORGANICS IMPACT FOR BASELINE SCENARIOS}

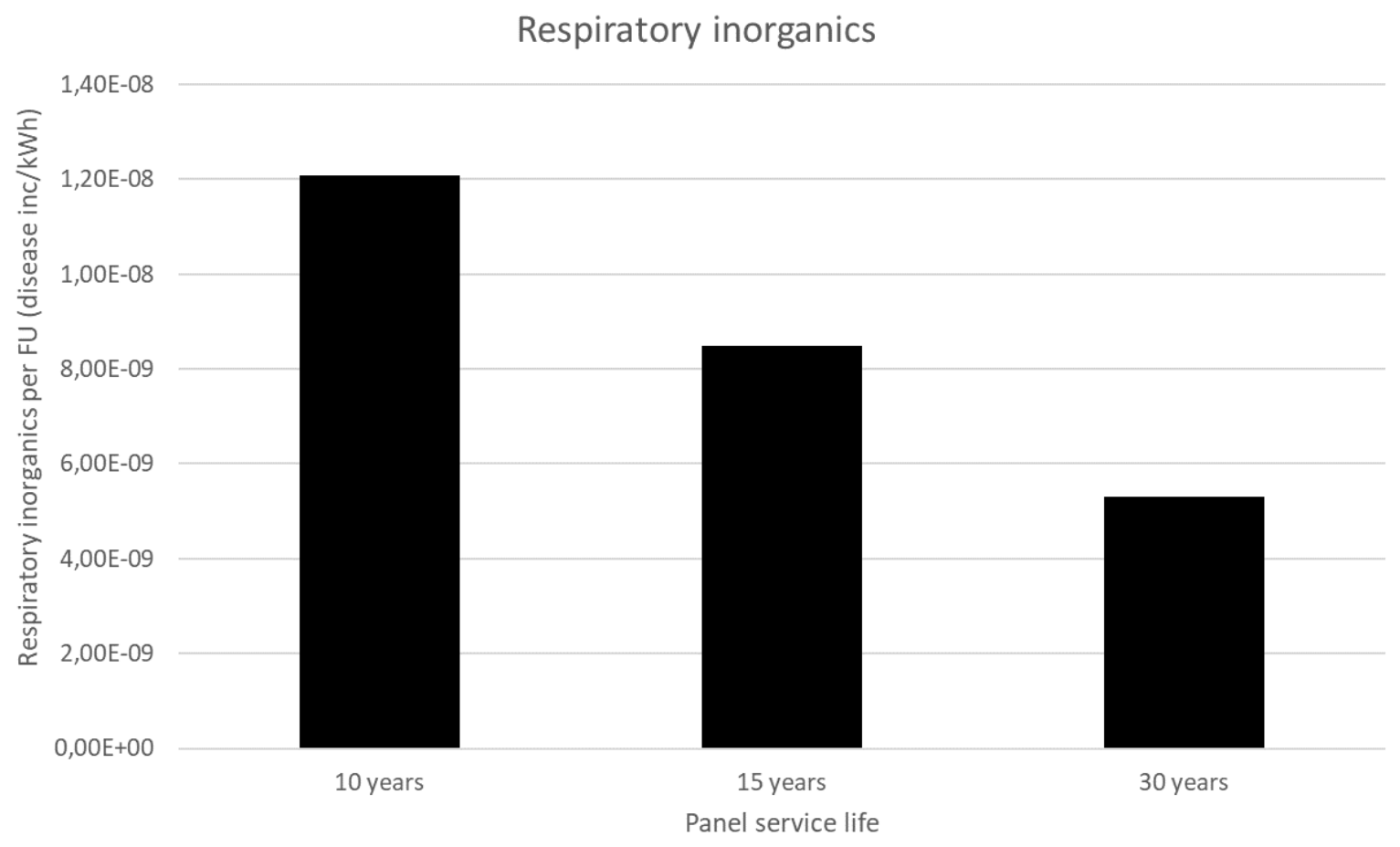

Environmental impact per FU with different panel service lifetimes, over a 30 -year period. The figure represents the respiratory inorganics impacts on human health per kWh (disease inc/kWh). PV technology: multi-crystalline silicon. System type: rooftop (flat roof). Panel efficiency rate: variable, increases $1,4 \%$ every year. Panel efficiency in the first cycle: $14,7 \%$. Degradation rate: $0.7 \%$. PV lifetime: variable, 10,15 , or 30 years. BOS lifetime: variable, 10 or 15 years. Installation location: Europe. Annual irradiation: $1.331 \mathrm{kWh} / \mathrm{m}^{2}$ (average for Europe). Performance ratio: 82\% (excluding degradation). 


\section{Ecotoxicity freshwater}

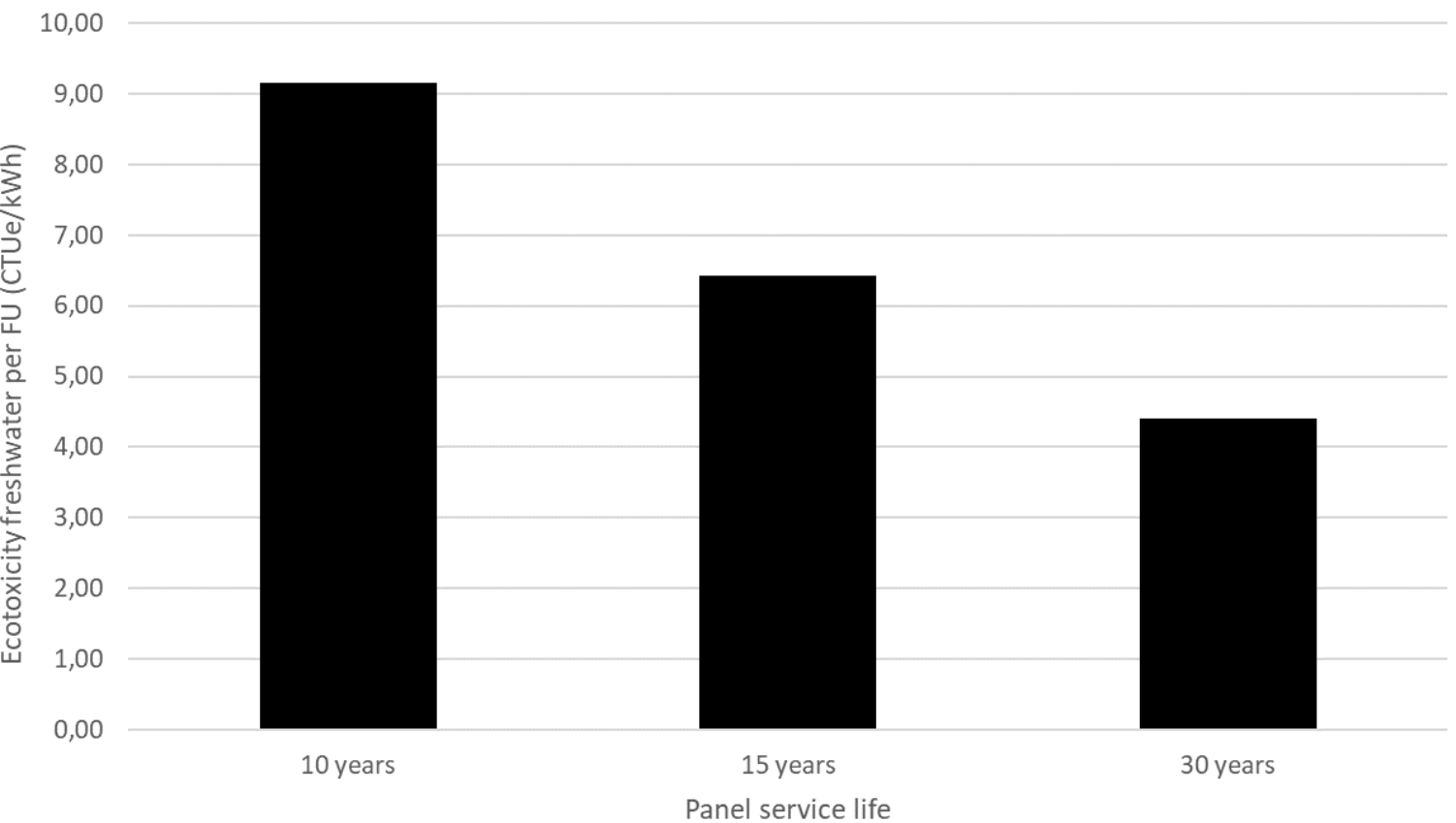

Environmental impact per FU with different panel service lifetimes, over a 30 -year period. The figure represents the ecotoxicity freshwater impacts in comparative toxicity unit for ecosystems per kWh (CTUe/kWh). PV technology: multi-crystalline silicon. System type: rooftop (flat roof). Panel efficiency rate: variable, increases $1,4 \%$ every year. Panel efficiency in the first cycle: $14,7 \%$. Degradation rate: $0.7 \%$. PV lifetime: variable, 10,15 , or 30 years. BOS lifetime: variable, 10 or 15 years. Installation location: Europe. Annual irradiation: $1.331 \mathrm{kWh} / \mathrm{m}^{2}$ (average for Europe). Performance ratio: $82 \%$ (excluding degradation). 


\section{ANNEX A - 8: GLOBAL WARMING POTENTIAL: SENSITIVITY ANALYSIS FOR TECHNOLOGY EVOLUTION}

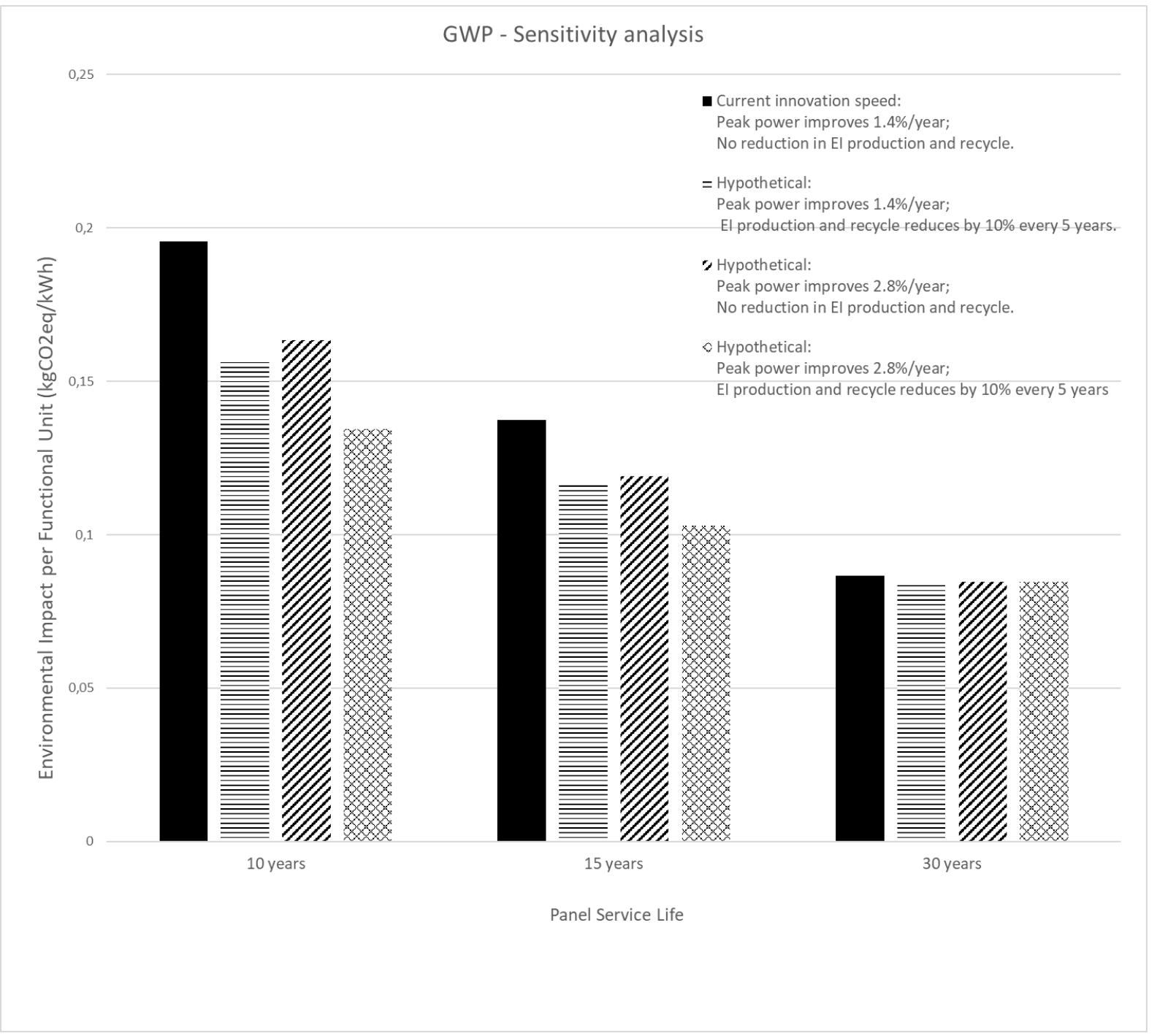

The global warming impact $\left(\mathrm{kg} \mathrm{CO}{ }_{2} \mathrm{eq}\right)$ per $\mathrm{kWh}$ for different panel service lifetimes (10, 15 , and 30 years) with different technology evolution projections for improvement in peak power and panel environmental impact (EI) reduction in manufacturing and recycling. 


\section{ANNEX A - 9: RESOURCE USE, MINERALS AND METALS IMPACT: SENSITIVITY ANALYSIS FOR TECHNOLOGY EVOLUTION}

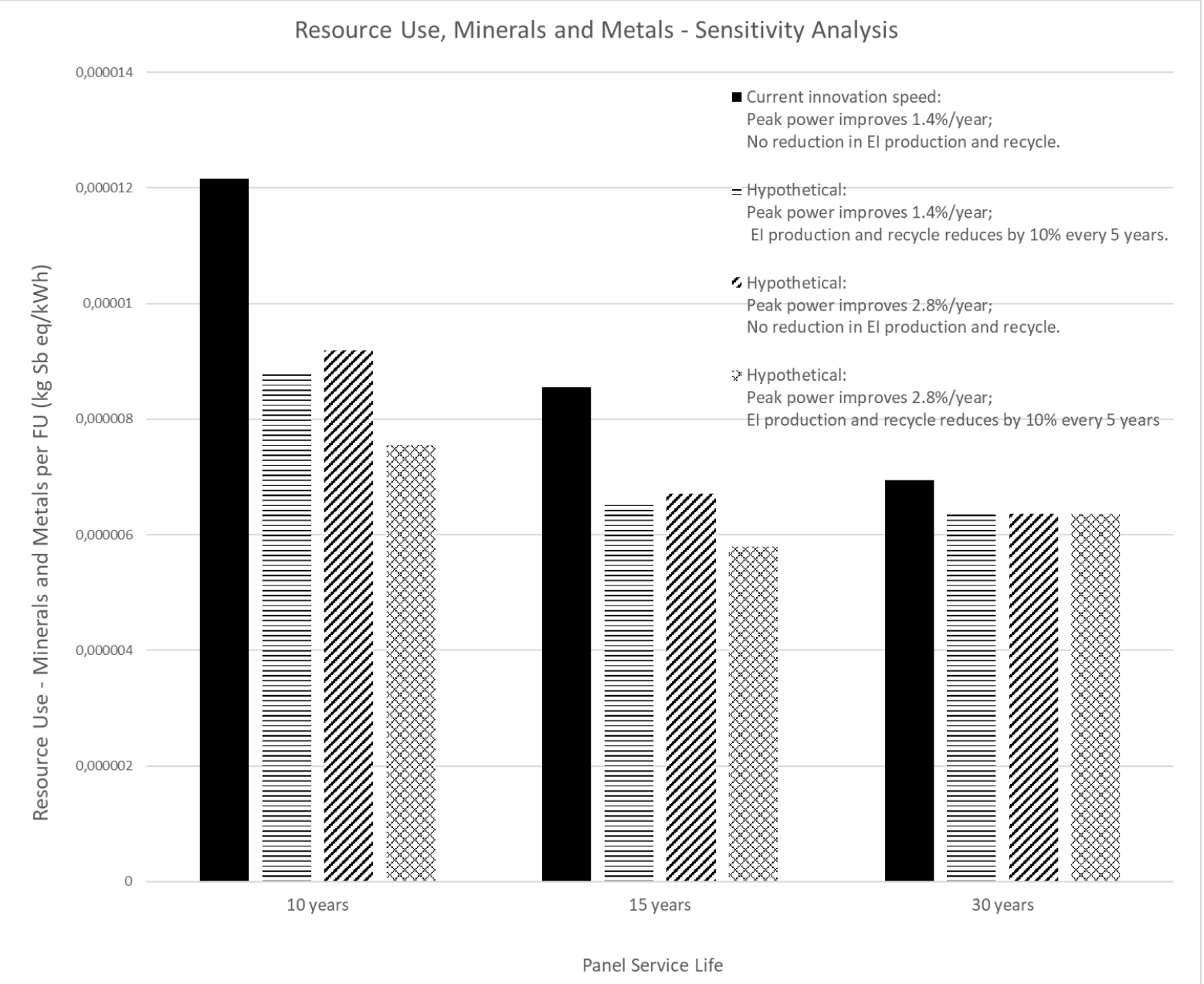

The resource use, minerals and metals impact (kg Sbeq) per kWh for different panel service lifetimes $(10,15$, and 30 years) with different technology evolution projections for improvement in peak power and panel environmental impact (EI) reduction in manufacturing and recycling. 


\section{ANNEX A - 10: RESOURCE USE, ENERGY CARRIERS IMPACT: SENSITIVITY ANALYSIS FOR TECHNOLOGY EVOLUTION}

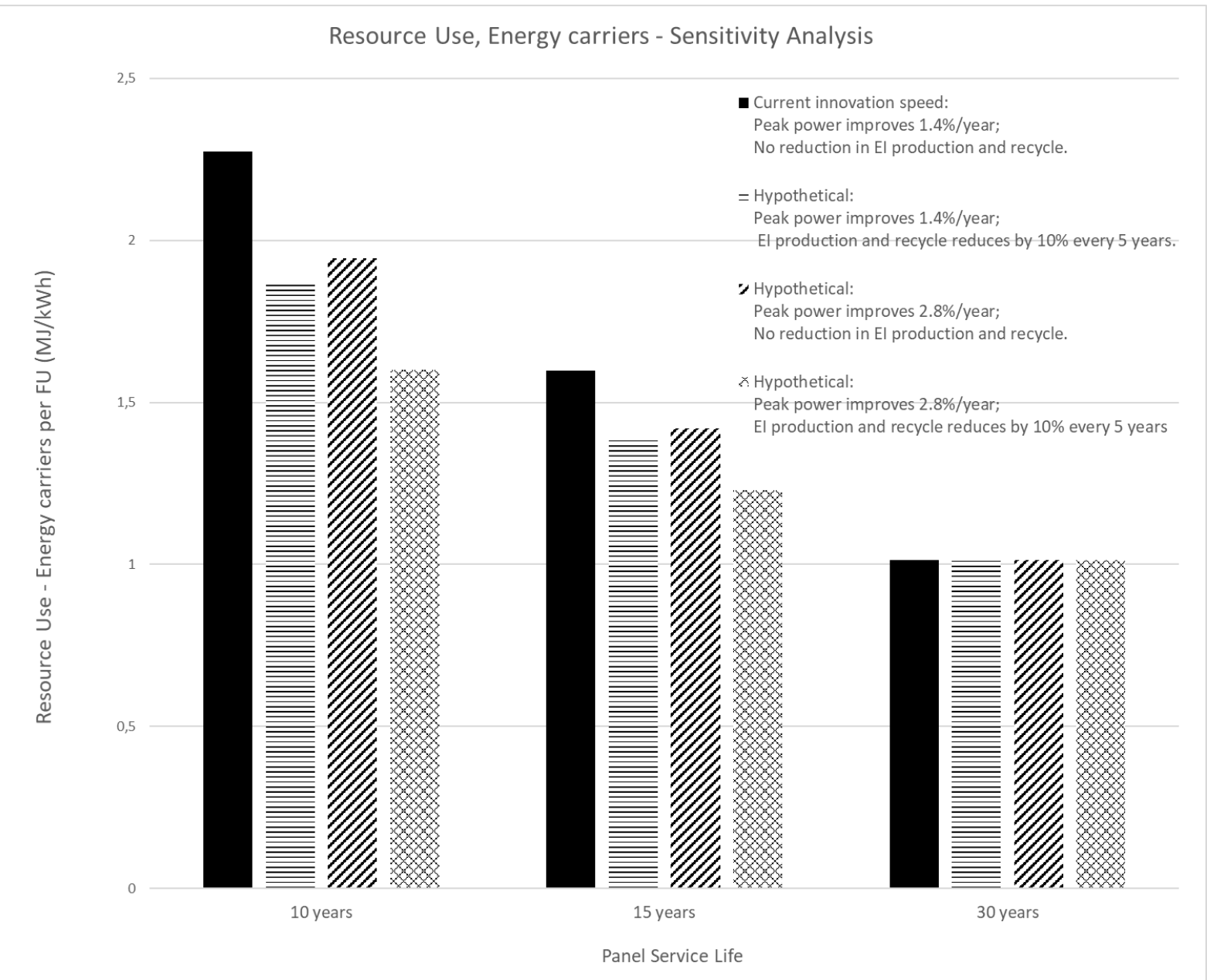

The resource use, energy carriers impact (MJ) per kWh for different panel service lifetimes (10, 15, and 30 years) with different technology evolution projections for improvement in peak power and panel environmental impact (EI) reduction in manufacturing and recycling. 


\section{ANNEX A - 11: RESPIRATORY INORGANICS IMPACT: SENSITIVITY ANALYSIS FOR TECHNOLOGY EVOLUTION}

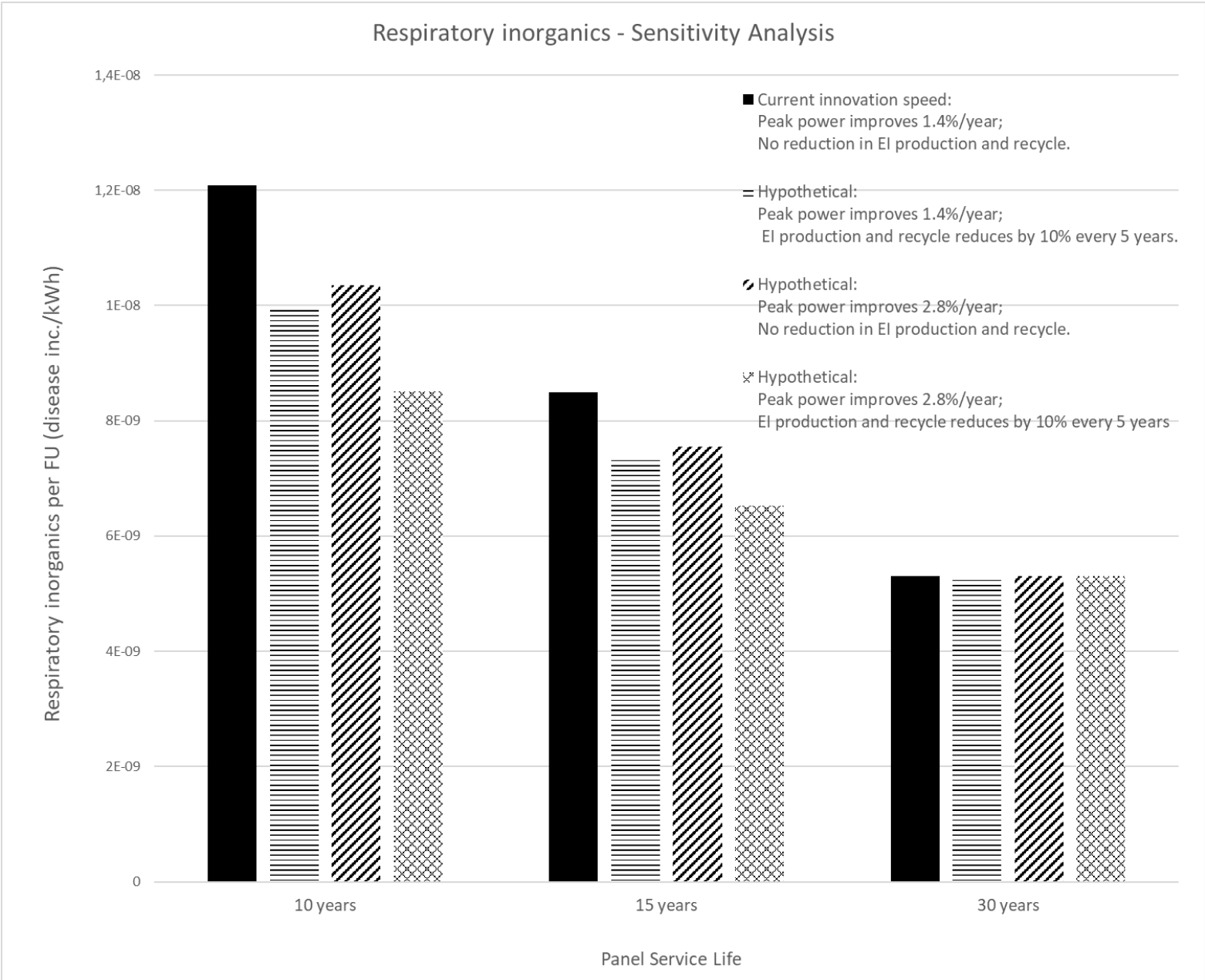

The respiratory inorganics impact on human health (disease incurrence) per kWh for different panel service lifetimes $(10,15$, and 30 years) with different technology evolution projections for improvement in peak power and panel environmental impact (EI) reduction in manufacturing and recycling. 


\section{ANNEX A - 12: FRESHWATER ECOTOXICITY IMPACT: SENSITIVITY ANALYSIS FOR TECHNOLOGY EVOLUTION}

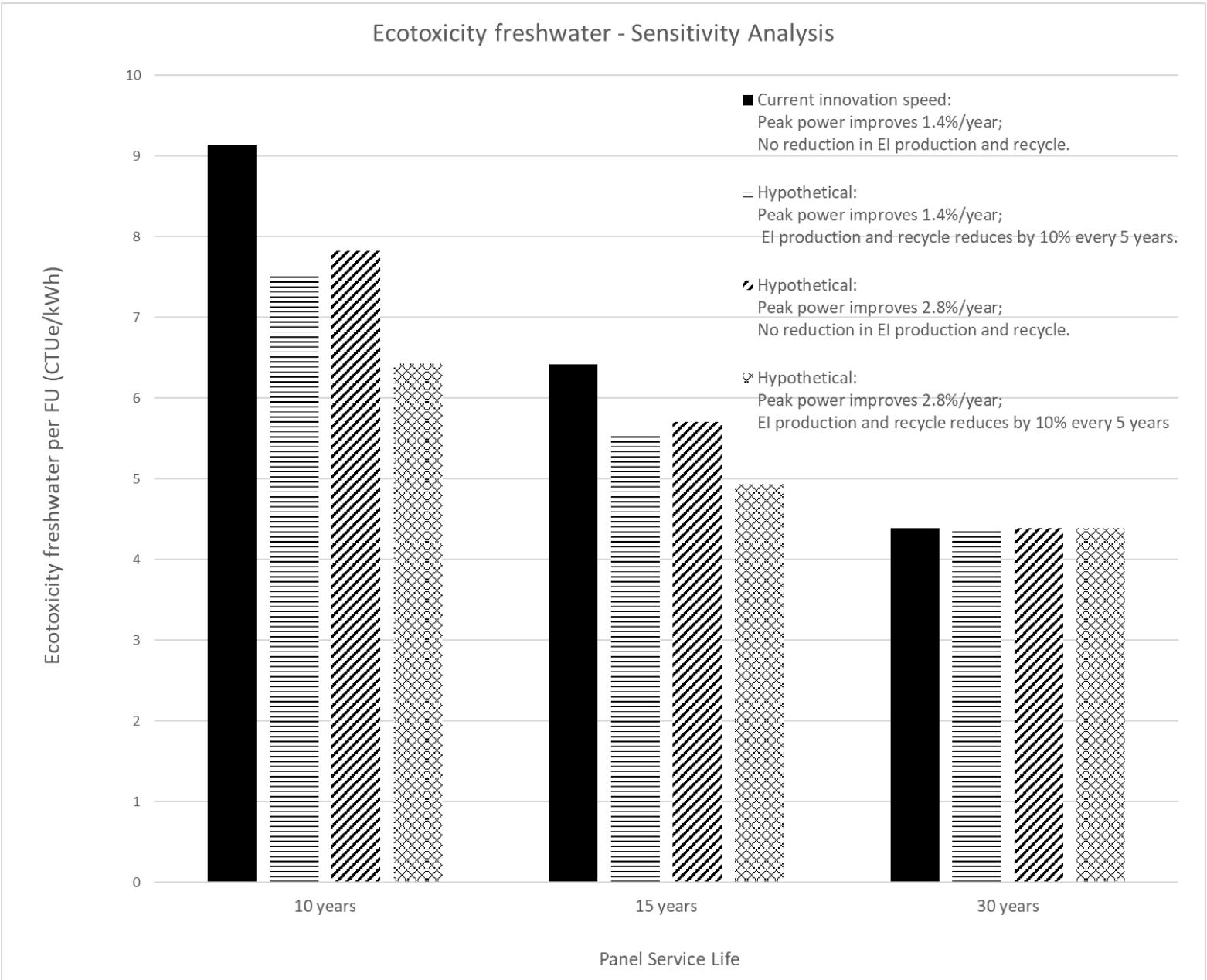

The ecotoxicity freshwater impact in comparative toxicity unit for ecosystems (CTUe) per kWh for different panel service lifetimes (10, 15, and 30 years) with different technology evolution projections for improvement in peak power and panel environmental impact (EI) reduction in manufacturing and recycling. 


\section{Annex Part B}

\section{ANNEX B - 1: WTP EVOLUTION FOR PREMATURELY DECOMMISSIONED PV, IN TERMS OF REMAINING LIFETIME AND POWER SHARE}

\begin{tabular}{|llllllllllllll|l|}
\hline \multicolumn{2}{|l|}{ Remaining lifetime of prematurely decommissioned PV panels: 30 years } \\
\hline a [\%] & 100 & 95 & 90 & 85 & 80 & 75 & 70 & 65 & 60 & 55 & 50 & 45 & 40 \\
\hline $\begin{array}{l}\text { WTP for } \\
\text { prematurely } \\
\text { decommissioned } \\
\text { PV panels [€/kWp] }\end{array}$ & 250 & 242 & 233 & 223 & 212 & 199 & 185 & 168 & 149 & 126 & 98 & 64 & 22 \\
\hline
\end{tabular}

\begin{tabular}{|c|c|c|c|c|c|c|c|c|c|c|c|c|c|}
\hline a [\%] & 100 & 95 & 90 & 85 & 80 & 75 & 70 & 65 & 60 & 55 & 50 & 45 & 40 \\
\hline $\begin{array}{l}\text { WTP for prematurely } \\
\text { decommissioned PV } \\
\text { panels [€/kWp] }\end{array}$ & 167 & 159 & 150 & 140 & 129 & 116 & 102 & 85 & 65 & 42 & -19 & -61 & \\
\hline
\end{tabular}

\begin{tabular}{|c|c|c|c|c|c|c|c|c|c|c|c|c|c|}
\hline a [\%] & 100 & 95 & 90 & 85 & 80 & 75 & 70 & 65 & 60 & 55 & 50 & 45 & 40 \\
\hline $\begin{array}{l}\text { WTP for } \\
\text { prematurely } \\
\text { decommissioned PV } \\
\text { panels [€/kWp] }\end{array}$ & 107 & 99 & 90 & 80 & 69 & 56 & 41 & 25 & 5 & -18 & -45 & -79 & $\begin{array}{c}- \\
121\end{array}$ \\
\hline
\end{tabular}

\begin{tabular}{|l|cccccccccccccc|c|}
\hline $\begin{array}{l}\text { Remaining lifetime of prematurely } \\
\text { a [\%] }\end{array}$ & 100 & 95 & 90 & 85 & 80 & 75 & 70 & 65 & 60 & 55 & 50 & 45 & 40 \\
\hline $\begin{array}{l}\text { WTP for prematurely } \\
\text { decommissioned PV } \\
\text { panels [€/kWp] }\end{array}$ & 30 & 22 & 13 & 3 & -8 & -21 & -35 & -52 & -72 & -95 & - & - & - \\
122 & 156 & 198 \\
\hline
\end{tabular}




\section{ANNEX B - 2: SELF-SUFFICIENCY AND WEIGHTED LCOE EVOLUTION OVER 30-YEAR HORIZON, FOR NEW PV IN A RESIDENTIAL SETTING}

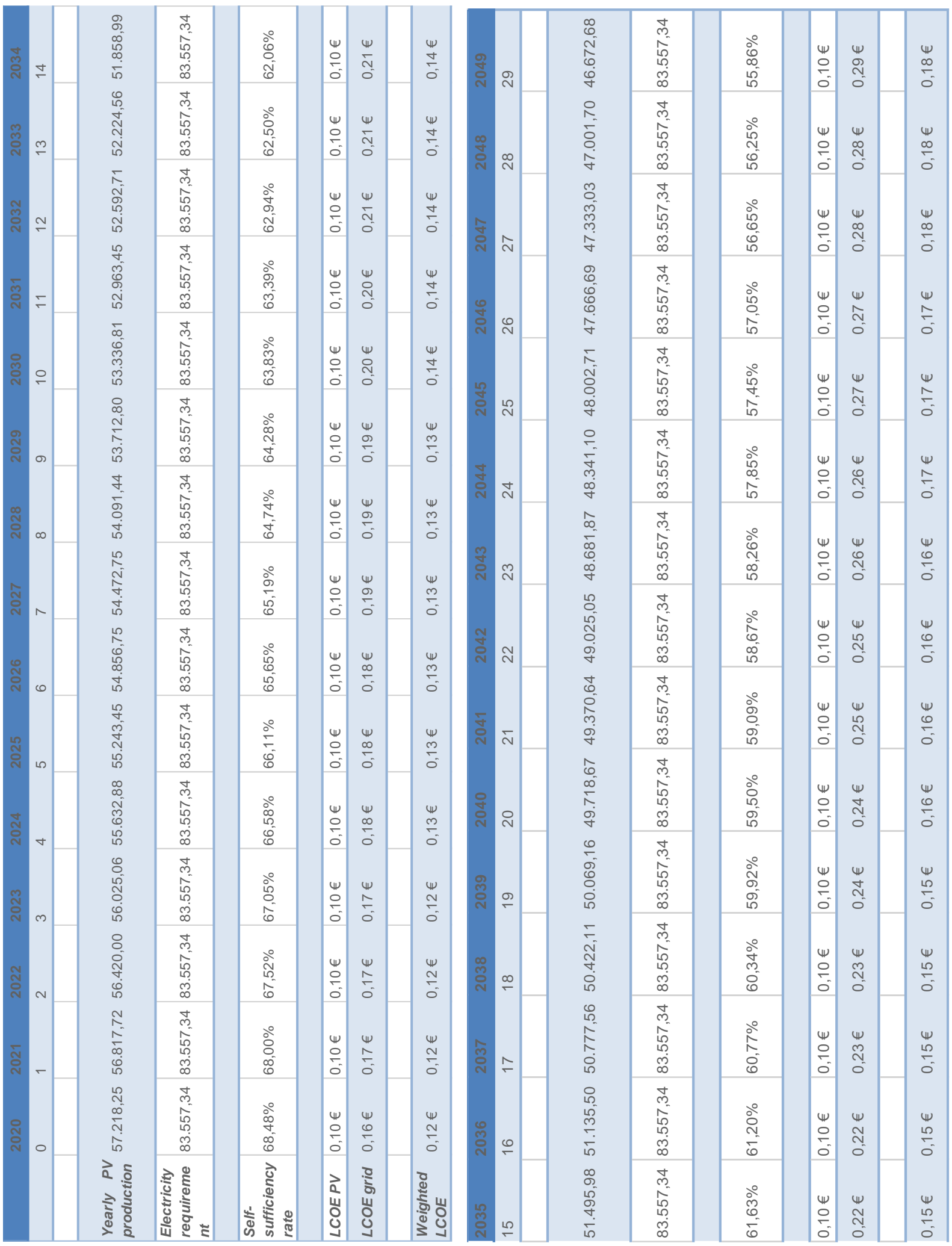




\section{REFERENCES}

1. Treeze. Product Environmental Footprint Category Rules (PEFCR): Photovoltaic Modules used in Photovoltaic Power Systems for Electricity Generation, commissioned by the Technical Secretariat of the PEF Pilot" Photovoltaic Electricity Generation". Uster, Switz. 2019;

2. $\quad$ Philipps S, Warmuth W. Photovoltaics Report Fraunhofer ISE. Fraunhofer Inst Sol Energy Syst ISE, Freibg im Breisgau, Ger Accessed Sep. 2018;15.

3. Reise C, Müller B, Moser D, Belluardo G, Ingenhoven P. Uncertainties in PV system yield predictions and assessments. IEA-PVPS, Rep IEA-PVPS T13-12. 2018;

4. European Commission. Waste from Electrical and Electronic Equipment (WEEE) [Internet]. [cited $2021 \mathrm{Jul}$ 8]. Available from: https://ec.europa.eu/environment/topics/waste-and-recycling/wasteelectrical-and-electronic-equipment-weee en

5. Franco M, Grosser S. A systematic literature review of the photovoltaic and electric vehicle battery value chains for the development of a circular economy in the PV industry, deliverable D1.1 within the H2020 CIRCUSOL project, funded by the European Commission. 2018.

6. Frischknecht R, Heath G, Raugei M, Sinha P, de Wild-Scholten M. Methodology guidelines on life cycle assessment of photovoltaic electricity. National Renewable Energy Lab.(NREL), Golden, CO (United States); 2016.

7. Tsanakas JA, van der Heide A, Radavičius T, Denafas J, Lemaire E, Wang K, et al. Towards a circular supply chain for PV modules: review of today's challenges in PV recycling, refurbishment and re-certification. Prog Photovoltaics Res Appl. 2020;28(6):454-64.

8. R. Frischknecht, P. Stolz, G. Heath, M. Raugei, P. Sinha M de W-S. Methodology Guidelines on Life Cycle Assessment of Photovoltaic Electricity, 4th edition. 2020.

9. VDMA. International Technology Roadmap for Photovoltaic (ITRPV) 2018 Results. 2019;

10. Tschümperlin L, Stolz P, Frischknecht R. Life cycle assessment of low power solar inverters (2.5 to $20 \mathrm{~kW}$ ). Uster, Switz Swiss Fed Off Energy. 2016;

11. European Commission. Results and deliverables of the Environmental Footprint pilot phase [Internet]. [cited 2021 Jul 8]. Available from: https://ec.europa.eu/environment/eussd/smgp/PEFCR_OEFSR_en.htm

12. Frischknecht R, Jungbluth N, Althaus H-J, Doka G, Dones R, Heck T, et al. The ecoinvent Database: Overview and Methodological Framework (7 pp). Int J Life Cycle Assess [Internet]. 2005;10(1):3-9. Available from: http://dx.doi.org/10.1065/lca2004.10.181.1

13. Stolz P, Frischknecht R, Wambach K, Sinha P, Heath $G$. Life cycle assessment of current photovoltaic module recycling. IEA PVPS Task 12, Int Energy Agency Power Syst Program Rep IEA-PVPS T1213. 2018;

14. Manfredi S, Allacker K, Pelletier N, Chomkhamsri K, de Souza DM. Product environmental footprint (PEF) guide. 2012;

15. Goedkoop M, De Schryver A, Oele M, Durksz S, de Roest D. Introduction to LCA with SimaPro 7. PRé Consult Netherlands. 2008;

16. Moreno Ruiz E, Valsasina L, Fitzgerald D, Brunner F, Symeonidis A, Bourgault G, et al. Documentation of changes implemented in the Ecoinvent database v3. 6. Ecoinvent Association, Zürich, Switzerland. 2019.

17. Fazio, S., Castellani, V., Sala, S., Schau, E., Secchi, M., Zampori, L. and Diaconu E. Supporting information to the characterisation factors of recommended EF Life Cycle Impact Assessment methods: New methods and differences with ILCD [Internet]. Luxembourg; 2018. Available from: 
https://publications.jrc.ec.europa.eu/repository/handle/JRC109369

18. European Commission. European Platform on Life Cycle Assessment (LCA) [Internet]. [cited $2021 \mathrm{Jul}$ 8]. Available from: https://ec.europa.eu/environment/ipp/lca.htm

19. European Commission. Product Environmental Footprint (PEF) Guide [Internet]. [cited 2021 Jul 8]. Available from: https://ec.europa.eu/environment/eussd/pdf/footprint/PEF methodology final draft.pdf

20. Kägi T, Dinkel F, Frischknecht R, Humbert S, Lindberg J, De Mester S, et al. Session "Midpoint, endpoint or single score for decision-making?"-SETAC Europe 25th Annual Meeting, May 5th, 2015. Int J Life Cycle Assess. 2016;21(1):129-32.

21. EUPV Platform. PV LCOE in Europe 2014-30. 2015.

22. VDMA. International Technology Roadmap for Photovoltaic (ITRPV): Results 2018 including maturity report 2019. 2019.

23. Magazine P. Module Price Index [Internet]. [cited 2021 Jul 8]. Available from: https://www.pvmagazine.com/module-price-index/

24. Vartiainen E, Masson G, Breyer C, Moser D, Román Medina E. Impact of weighted average cost of capital, capital expenditure, and other parameters on future utility-scale PV levelised cost of electricity. Prog photovoltaics Res Appl. 2020;28(6):439-53. 

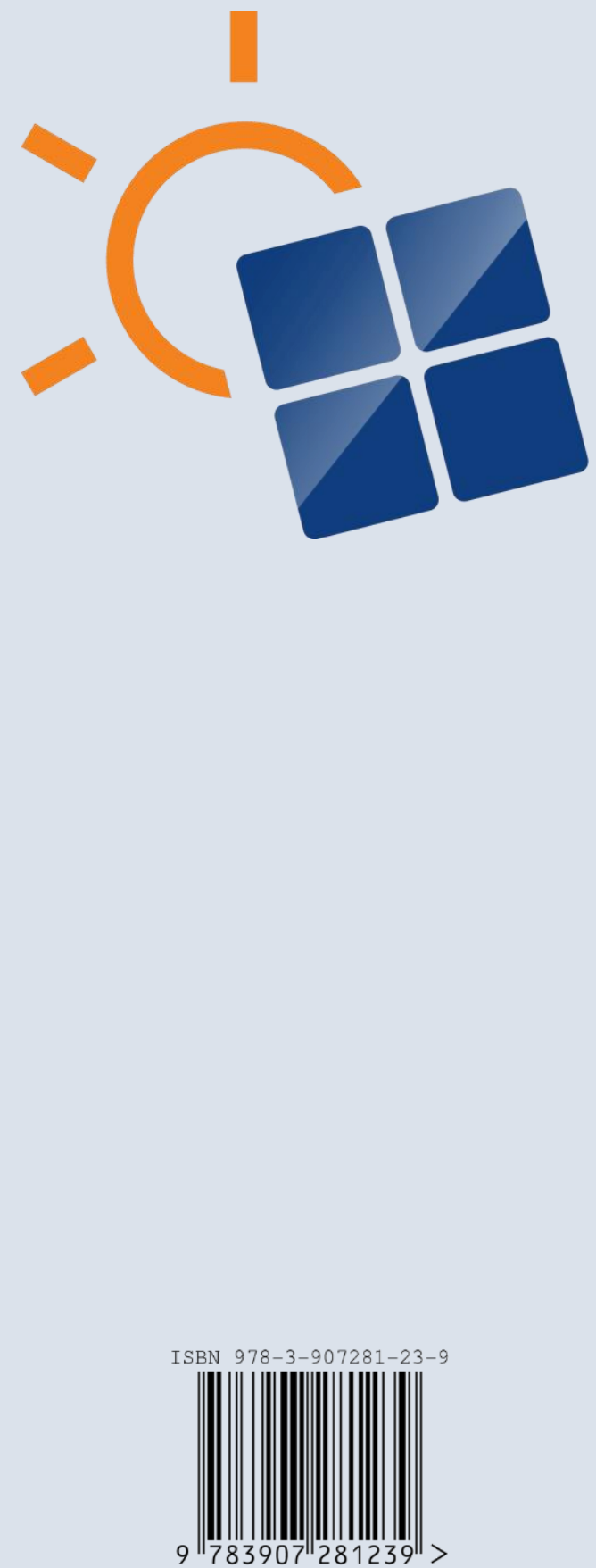